\title{
Novel Players in the Aging Synapse: Impact on Cognition
}

\author{
Mariana Temido-Ferreira, PhD, ${ }^{1}$ Joana E. Coelho, PhD, ${ }^{1}$ Paula A. Pousinha, PhD, ${ }^{2}$ and Luísa V. Lopes, PhD ${ }^{1}$
}

While neuronal loss has long been considered as the main contributor to age-related cognitive decline, these alterations are currently attributed to gradual synaptic dysfunction driven by calcium dyshomeostasis and alterations in ionotropic/metabotropic receptors. Given the key role of the hippocampus in encoding, storage, and retrieval of memory, the morpho- and electrophysiological alterations that occur in the major synapse of this network-the glutamatergic-deserve special attention. We guide you through the hippocampal anatomy, circuitry, and function in physiological context and focus on alterations in neuronal morphology, calcium dynamics, and plasticity induced by aging and Alzheimer's disease (AD). We provide state-of-the art knowledge on glutamatergic transmission and discuss implications of these novel players for intervention. A link between regular consumption of caffeine - an adenosine receptor blocker-to decreased risk of AD in humans is well established, while the mechanisms responsible have only now been uncovered. We review compelling evidence from humans and animal models that implicate adenosine $A_{2 A}$ receptors $\left(A_{2 A} R\right)$ upsurge as a crucial mediator of age-related synaptic dysfunction. The relevance of this mechanism in patients was very recently demonstrated in the form of a significant association of the $\mathrm{A}_{2 \mathrm{~A}} \mathrm{R}$-encoding gene with hippocampal volume (synaptic loss) in mild cognitive impairment and $A D$. Novel pathways implicate $A_{2 A} R$ in the control of mGluR5-dependent NMDAR activation and subsequent $\mathrm{Ca}^{2+}$ dysfunction upon aging. The nature of this receptor makes it particularly suited for long-term therapies, as an alternative for regulating aberrant mGluR5/NMDAR signaling in aging and disease, without disrupting their crucial constitutive activity.

Keywords: aging, adenosine $\mathrm{A}_{2 \mathrm{~A}}$ receptor, synaptic plasticity, hippocampus, memory, NMDA receptor, mGluR5 receptor

\section{Introduction}

A GING HAS BEEN widely associated with cognitive decline and synaptic dysfunction and is the main risk factor for Alzheimer's disease (AD). One brain region that is clearly crucial for normal episodic memory is the hippocampus. This medial temporal lobe (MTL) structure has been shown to undergo functional changes over the lifespan. During normal aging, the numbers of primary hippocampal glutamatergic neurons counted stereologically in humans, monkey, or rats do not change significantly (see Morrison and Hof ${ }^{1}$ ). If cell numbers are not affected, memory impairment is probably due to the subtle changes known to occur at the synapse that result in altered mechanisms of plasticity.

\section{The Hippocampus}

The hippocampus is a three-layered structure that is mutually connected to other cortical and subcortical areas (Fig. 1A, B). The trisynaptic pathway from the dentate gyrus (DG) to the CA3 via mossy fibers and onward to CA1 via Schaffer collaterals is the principal feed-forward circuit involved in the process of information through the hippocampus $^{2}$ (Fig. 1C, D). The hippocampus receives unidirectional input from the entorhinal cortex (EC), where layer II neurons project to DG granule cells via the perforant path $^{2,3}$ and layer III neurons project to CA1 neurons via the temporoammonic path (perforant path to CA1). ${ }^{2}$ CA1 pyramidal cells - the major output neurons-project back to deep layers of the EC and to various subcortical and cortical areas via the subicular complex. ${ }^{2}$

\footnotetext{
${ }^{1}$ Instituto de Medicina Molecular João Lobo Antunes, Faculdade de Medicina, Universidade de Lisboa, Lisboa, Portugal.

${ }^{2}$ Institut de Pharmacologie Moléculaire et Cellulaire (IPMC), CNRS UMR7275, Université Côte d'Azur, Valbonne, France.

(c) Mariana Temido-Ferreira, et al. 2019; Published by Mary Ann Liebert, Inc. This Open Access article is distributed under the terms of the Creative Commons Attribution Noncommercial License (http://creativecommons.org/licenses/by-nc/4.0/) which permits any noncommercial use, distribution, and reproduction in any medium, provided the original author(s) and the source are cited.
} 

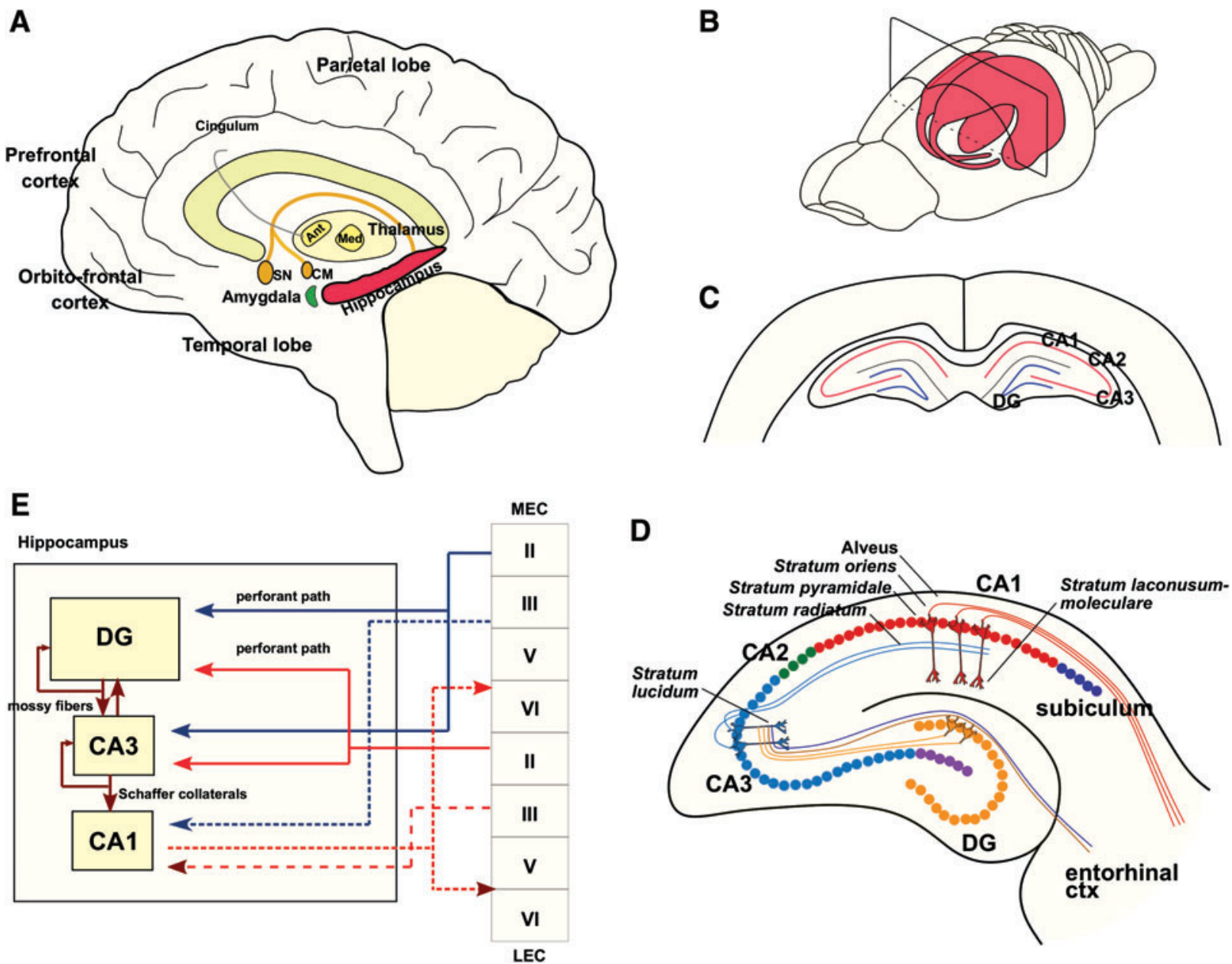

FIG. 1. Hippocampal anatomy and circuitry. (A) Principal anatomy of the human hippocampal memory systems and the brain regions involved in learning and memory. (B) Schematic rat brain with the hippocampal formation highlighted. (C) Schematic hippocampal slice. (D) Hippocampal slice with different areas and layers. (E) Schematic representation of the hippocampal trisynaptic circuit. First, granule neurons in the hippocampal dentate gyrus receive afferent inputs, via the performant path, from the layer II of the lateral and MEC. Next, granule neurons project to the CA3 pyramidal neurons via mossy fibers and, ultimately, CA1 neurons receive inputs from the CA3 by the Schaffer collaterals, by the contralateral hippocampus through associational/commissural fibers or direct inputs from the performant path. To close the hippocampal synaptic loop, CA1 pyramidal neurons project back to the EC. Ant, anterior thalamic nuclei; CA, cornu ammonis; CM, corpus mammillaris; DG, dentate gyrus; EC, entorhinal cortex; LEC, lateral entorhinal cortex; LPP, lateral performant pathway; MEC, medial entorhinal cortex; Med, medial thalamic nuclei; MPP, medial performant pathway; Mtt, mamillothalamic tract; SN, septal nucleus. Adapted from Lavenex and Amaral. ${ }^{7}$ Color images are available online.

The DG has three distinct layers (molecular, granular, and polymorphic) and mainly consists of granule cells. The axons of the DG granule cells form the mossy fiber system and project both to the CA3 and back onto granule cells, thus forming a recurrent network. ${ }^{2,4}$ In addition, the DG receives inputs from the contralateral hippocampus via commissural projections. ${ }^{2,4}$ Axon collaterals of CA3 pyramidal neurons synapse onto other CA3 neurons, forming a recurrent autoassociative network, whereas CA3 neurons projecting back to the dentate network form a heteroassociative network. ${ }^{2,5} \mathrm{CA} 1$ pyramidal neurons not only receive information which has been preprocessed in the subnetworks of the DG and $\mathrm{CA} 3$ but also receive direct projections from the $\mathrm{EC}$, suggesting that the function of the CA1 neurons includes comparing new information from the EC with stored information via $\mathrm{CA} 3$ relevant in detection of error, mismatch, and novelty ${ }^{2,6}$ (Fig. 1E). The crucial role of this redundant feed-forward circuit is crucial for learning and memory and may also underlie its high vulnerability to insults ${ }^{2,7}$ (Fig. 1E).

\section{Synaptic organization}

The integrative properties of neurons depend strongly on the number, proportions, and distribution of excitatory 
and inhibitory inputs they receive. A single CA1 pyramidal cell has $\sim 12,000 \mu \mathrm{m}$ dendrites and receives around 30,000 excitatory and 1,700 inhibitory inputs, of which $40 \%$ are concentrated in the perisomatic region and $20 \%$ on dendrites in the stratum lacunosum-moleculare. ${ }^{8}$ The density of dendritic spines and synapses on CA1 pyramidal neurons is highest in the stratum radiatum and stratum oriens. ${ }^{9}$

Hippocampal neurons mainly release glutamate or gamma-aminobutyric acid (GABA). ${ }^{9}$ These neuron types are, most of the times, easily identified due to significant differences in (a)symmetry of synapses, excitatory or inhibitory effect, relative somatic abundance within an area, presence of dendritic spines, and local or projecting nature of the axons. ${ }^{10}$

The cell bodies of glutamatergic pyramidal neurons are organized in a three-to-five cell-deep laminar arrangement in stratum pyramidale and have orthogonal dendrites from stratum oriens to stratum lacunosum moleculare, thus receiving afferent inputs from several intrinsic and extrinsic sources across well-defined dendritic domains. ${ }^{11}$ In contrast, inhibitory interneurons (approximately 10-15\% of the total cell population), which release the neurotransmitter GABA, have their cell bodies distributed throughout all major strata but they integrate from a more restricted intrinsic and extrinsic afferent input repertoire. However, some interneurons possess axons that cross considerable distances to innervate distinct subcellular compartments or alternatively form long-range projections that extend beyond their original central location to ramify within both cortical and subcortical structures. ${ }^{11}$

Hippocampal interneurons can be divided into several types: neurogliaform family (32.2\%), SOM expressing $(9.3 \%)$, PV expressing (23.9\%), CCK expressing $(13.9 \%)$, and interneuron-specific $(19.4 \%) .{ }^{11}$ Despite being the minority, this diverse neuronal population serves as a major determinant of virtually all aspects of neocortical circuit function and regulation. ${ }^{11}$

The hippocampus receives multiple direct and indirect projections that are crucial to hippocampal function regulation. Dopaminergic projections from both the substantia nigra pars compacta and the ventral tegmental area are important for memory processing. ${ }^{12,13}$ Also, activation of cholinergic projections activation from the medial septum/diagonal band is sufficient to induce $40-\mathrm{Hz}$ network oscillations in the hippocampus in vitro, thus playing an important role in hippocampal memory processing. ${ }^{14}$ Serotonergic projections from the median raphe nucleus to the ventral hippocampus have also been consistently described $^{15}$ and are involved in the retrieval of fear memories. ${ }^{16}$

\section{Glutamatergic synapses}

Electron microscopy images reveal structural differences between the glutamatergic pre- and postsynaptic components (Fig. 2A). The presynaptic element is easily identified by the presence of neurotransmitter-containing vesicles, generally of relatively uniform size. These vesicles aggregate near a membrane specialization, identified by a more electrodense thickening, reflecting the presence of membrane proteins necessary for exocytosis-“active zone" (Fig. 2A). Among these are proteins that interact with vesicular partners (SNARE proteins), as well as voltage-dependent channels that mediate the influx of $\mathrm{Ca}^{2+}$, which ultimately triggers exocytosis upon an action potential. In addition, mitochondria are frequently present due to the local high energetic demands coupled to transmitter release (transmitter synthesis, vesicular packaging, exocytosis, and reuptake). ${ }^{9,17}$

On the postsynaptic side, the membrane is more electrodense than the presynaptic membrane (Fig. 2A). This postsynaptic density, or PSD, is a relatively detergentresistant structure, $50 \mathrm{~nm}$ thick, that scaffolds as many as 100 different proteins, among them the glutamate receptors. $^{9,18,19}$ In inhibitory neurons gephyrin is the equivalent postsynaptic scaffolding molecule. ${ }^{20}$

Glutamate receptors. Glutamate is packaged into synaptic vesicles in the presynaptic terminals, and released into the synaptic cleft through the docking of synaptic vesicles to the membrane at the active zone. Glutamate then activates postsynaptic glutamate receptors to regulate several neuronal functions, from neuronal migration to excitability and plasticity. ${ }^{18}$ Glutamate receptors are highly complex transmembrane proteins that can be divided into two main categories: voltage-sensitive ionotropic glutamate receptors (iGluRs; glutamate-gated ion channels) and ligand-sensitive metabotropic glutamate receptors (mGluRs; glutamate-activated $\mathrm{G}$ protein-coupled receptors [GPCRs]) (Fig. 2B).

iGluRs mediate the fast excitatory transmission, acting as cation channels that open upon glutamate binding. AMPA ( $\alpha$-amino-3-hydroxy-5-methyl-4-isoxazolepropionic acid) receptors are the first iGluRs activated, leading to sodium influx and consequently postsynaptic membrane depolarization (Fig. 2B-D). Following the initial AMPARmediated depolarization, NMDA (N-methyl-D-aspartate) receptors become activated due to removal of the voltage-dependent physical occlusion by magnesium of the channel pore and are permeable to sodium and calcium ions (Fig. 2B-D). ${ }^{18}$ Kainate receptors also mediate synaptic transmission, at a smaller extent, through the entry of sodium and calcium (Fig. 2B-D). Generally, AMPA receptors mediate fast ( $<10$ mseconds) synaptic transmission, while NMDA and kainate receptors mediate slow (10-100 mseconds) synaptic transmission. ${ }^{18}$

In addition, mGluRs activation also modulates neuronal excitability and synaptic transmission. mGluRs are slower players since they exert their effects through recruitment of second messenger systems, gene expression, and protein synthesis. Eight mGluR subtypes (mGluR1-8) 


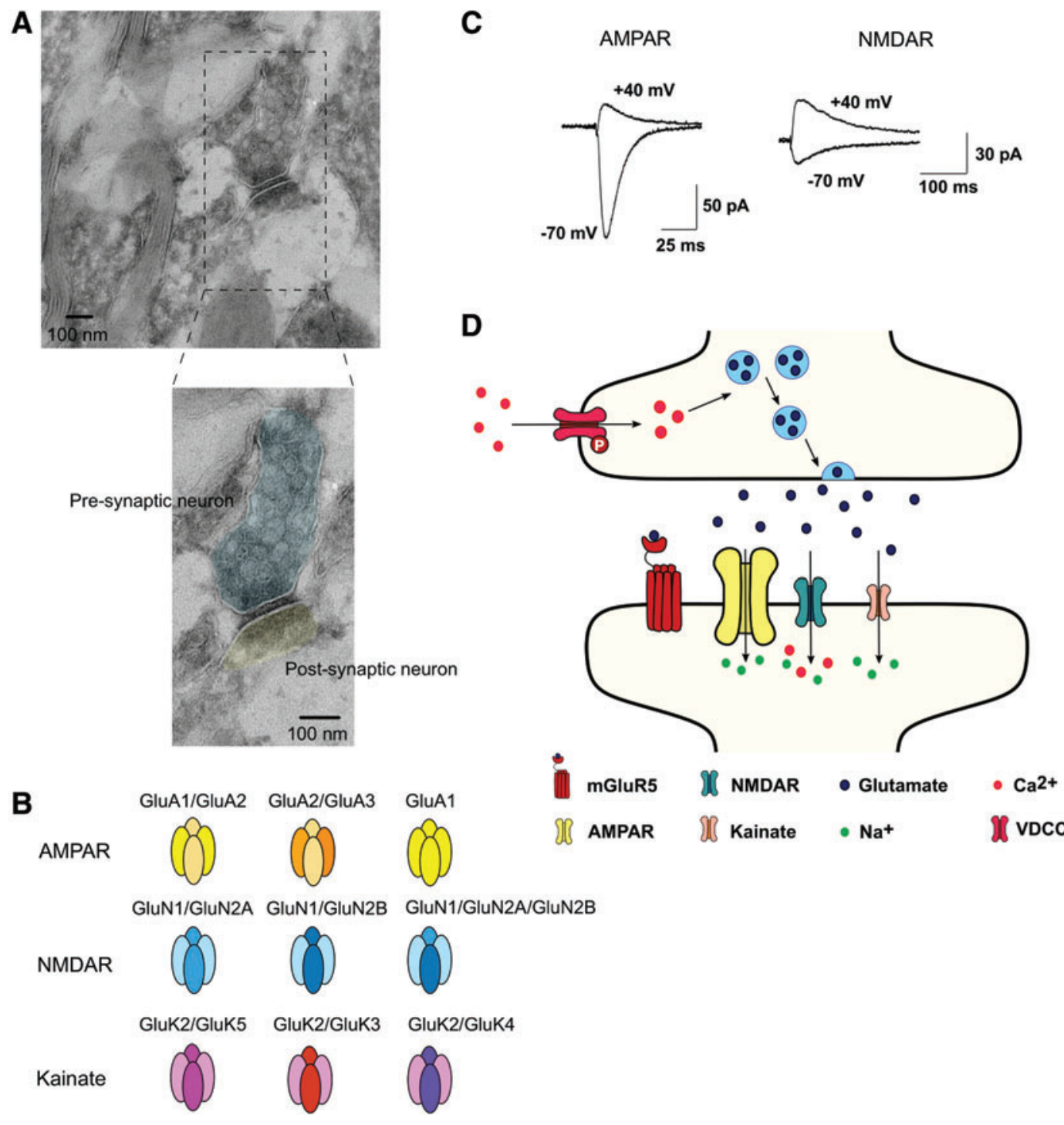

FIG. 2. Glutamatergic pre- and postsynaptic neurons are very distinct structurally and functionally. (A) Electron micrographs of the CA1 area of the hippocampus showing morphological differences between pre- and postsynaptic components. The presynaptic element is easily identified by the presence of neurotransmitter-containing vesicles, generally of relatively uniform size. These vesicles aggregate near a membrane specialization that can be identified as a thickening, reflecting the presence of membrane proteins necessary for exocytosis — "active zone." On the postsynaptic side, there is also an increased density of the membrane-postsynaptic density, a relatively detergent-resistant structure containing glutamate receptors and associated macromolecules (image kindly provided by Andreia Pinto, IMM JLA). (B) Most abundant subunit composition of ionotropic receptors AMPA, NMDA, and kainate in the hippocampus. ${ }^{8}$ (C) Representative AMPAR and NMDAR excitatory postsynaptic currents measured in a rat CA1 hippocampal neuron at -70 and $+40 \mathrm{mV} .^{100}$ (D) Schematic diagram of a glutamatergic synapse. Calcium influx through activation of presynaptic VDCC drives docking of the glutamate vesicles to the membrane. Once released, glutamate acts on postsynaptic AMPA (sodium influx), NMDA (sodium and calcium influx), kainate (sodium influx), and metabotropic receptors; adapted from Hassel and Dingledine. ${ }^{18}$ AMPA, $\alpha$-amino-3-hydroxy-5-methyl-4-isoxazolepropionic acid; GluA, AMPA receptor subunit; GluK, kainate receptor subunit; GluN, NMDA receptor subunit; NMDA, N-methylD-aspartate; VDCC, voltage-dependent calcium channels. Color images are available online.

are differentially expressed in specific regions in the central nervous system (CNS), being divided into three subgroups based on sequence homology, G proteincoupling, and ligand selectivity (Fig. 2D). ${ }^{18}$ Group I mGluRs (mGluR1 and 5) are widely expressed postsynaptically, being preferentially associated with $\mathrm{Gq} / \mathrm{Gs}{ }^{18}$
Group I mGluRs trigger the activation of phospholipase C (PLC), which then leads to calcium mobilization from endoplasmic reticulum and protein kinase $\mathrm{C}$ (PKC) activation. ${ }^{18}$ Glutamatergic soma and synapses can be labeled by a wide variety of markers listed in Table 1. 
Table 1. Glutamatergic Synaptic Markers, Localization, and Role

\begin{tabular}{|c|c|c|}
\hline Marker & Localization & Role \\
\hline AMPAR GluA1 & PSD & AMPA receptor $\mathrm{R} 1$ subunit \\
\hline CaMKII & Neuronal soma & $\begin{array}{l}\text { Protein kinase regulated by the } \mathrm{Ca}^{2+} / \text { calmodulin complex; involved } \\
\text { in } \mathrm{Ca}^{2+} \text { homeostasis and in learning and memory processes }{ }^{32}\end{array}$ \\
\hline Glutaminase & $\begin{array}{l}\text { Neuronal soma } \\
\text { Astrocytes }\end{array}$ & Enzyme that generates glutamate from glutamine ${ }^{18}$ \\
\hline Glutamine synthase & Astrocytes & $\begin{array}{l}\text { Enzyme that catalyzes the condensation of ammonia and glutamate } \\
\text { to form glutamine }\end{array}$ \\
\hline $\begin{array}{l}\text { NMDAR } \\
\text { GluN1 }\end{array}$ & PSD & NMDA receptor N1 subunit \\
\hline PSD95 & PSD & $\begin{array}{l}\text { Fibrous specialization of the submembrane cytoskeleton that adheres } \\
\text { to the postsynaptic membrane; regulation of adhesion, control } \\
\text { of receptor clustering, and regulation of receptor function }{ }^{9,18,19}\end{array}$ \\
\hline vGluT & Pre-synaptic neuron & Transports cytoplasmic glutamate into vesicles ${ }^{35}$ \\
\hline
\end{tabular}

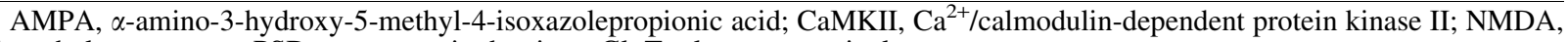
$\mathrm{N}$-methyl-D-aspartate; PSD, postsynaptic density; vGluT, glutamate vesicular transporter.

\section{Synaptic plasticity}

Synaptic plasticity can be defined as activity-dependent modifications in the efficacy and strength of synaptic transmission of preexisting synapses. ${ }^{21}$ Long-term synaptic plasticity can last from minutes to several days and even years. $^{22-24}$ These synaptic plasticity processes have long been correlated with memory performance and are proposed to be a main neurophysiological correlate of memory. ${ }^{21,25}$

Hebbian plasticity. The Schaffer collaterals-CA1 synapse is undoubtedly the most well-characterized and well-studied glutamatergic synapse of the hippocampus. In the last decades, many in vitro electrophysiological studies have described the events underlying long-term potentiation (LTP) and long-term depression (LTD) phenomena. These mechanisms, found and studied in animal models, have also been described in humans. ${ }^{26}$ Importantly, blockade of proteins involved in either LTP or LTD mechanisms disrupts learning. ${ }^{27-30}$

The most extensively studied and characterized forms of synaptic plasticity are the LTP and LTD in the Schaffer collaterals-CA1 region of the hippocampus. LTP is defined as the long-lasting enhancement in synaptic transmission between two neurons following a continuous and strong stimulation (high-frequency stimulation or theta-burst stimulation), while LTD reflects a longlasting decrease in the efficiency of synaptic transmission following a continuous weak stimulation (LFS: lowfrequency stimulation).

Postsynaptically, LTP and LTD processes begin with a depolarization of the membrane due to $\mathrm{Na}^{+}$influx through AMPAR activation, which releases the $\mathrm{Mg}^{2+}$ block from NMDAR. Although both forms require AMPAR and NMDAR activation, it is the spatiotemporal nature of the intracellular $\mathrm{Ca}^{2+}$ rise that dramatically impacts the direction of plasticity. ${ }^{31}$ The huge increase in $\mathrm{Ca}^{2+}$ influx elicited by strong activation of NMDAR acti- vates calcium/calmodulin-dependent protein kinase II (CaMKII), a key component of the molecular machinery for LTP, since LTP induction was prevented in knockout (KO) mice lacking a critical CaMKII subunit. ${ }^{32}$ The modest increase in $\mathrm{Ca}^{2+}$ influx observed upon weak stimulation instead drives activation of phosphatases, such as protein phosphatase 1 and $2 .^{33}$ Thus, the probability of a given synapse to undergo LTP or LTD is a function of kinases versus phosphatases activation. Consequently, in LTP or LTD AMPAR phosphorylation can be regulated bidirectionally, with LTP increasing phosphorylation and LTD decreasing phosphorylation. ${ }^{34-37}$

Homeostatic plasticity. Most studies of long-term changes in synaptic strength have focused on Hebbian mechanisms, where these changes occur in a synapsespecific manner. Although Hebbian mechanisms are necessary for modulating neuronal circuitry selectively, they might not be sufficient since they tend to destabilize the activity of neuronal networks. An increase in synaptic strengths, such as in LTP, would increase the excitatory drive on to a postsynaptic cell, making it more likely to fire. This in turn would increase the likelihood of more LTP; thus positive feedback would quickly saturate the system, resulting in a hyperactive state with saturated synaptic inputs. Conversely, excessive LTD would also proliferate, resulting in a silent state with inputs fully depressed. ${ }^{38}$

Homeostatic plasticity acts as a compensatory stabilizing mechanism that, using a negative feedback system, keeps the activity of the network within a dynamic range. ${ }^{39,40} \mathrm{Sev}-$ eral forms of homeostatic plasticity have been identified and include mechanisms that regulate neuronal excitability, stabilize total synaptic strength, and influence the rate and extent of synapse formation. ${ }^{41}$ These forms of homeostatic plasticity are likely to complement Hebbian mechanisms to allow the modification of neuronal networks selectively. ${ }^{41}$ In essence, the whole synaptic population is equally affected, such that the overall sum of synaptic strengthening and therefore activity of a neuron is changed but the relative 
weighed differences between synapses is preserved: the computational and storage capacity of the network is not compromised and homeostatic plasticity will not be in conflict with or erase the information set by Hebbian plasticity. ${ }^{41}$

\section{The Aged Glutamatergic Synapse}

According to the World Health Organization (WHO), by 2020 , the number of people aged 60 years and older will outnumber children younger than 5 years. Moreover, between 2015 and 2050, the proportion of the world's population over 60 years will nearly double from $12 \%$ to $22 \%$. Aging is, in fact, the main risk factor for $\mathrm{AD}^{4}{ }^{42}$ These profound demographic changes have placed "the aging process" as one of the big challenges for scientific research nowadays. Although aging affects the entire body, its impact on brain and cognition has a profound effect on quality of life of the individuals. Much work has been focused on the hippocampus, as age-related decline in performance dependent on this region is consistently found across species and tasks. ${ }^{43-48}$

These age-related memory impairments can be explained, in part, by changes in neural plasticity or cellular alterations that directly affect mechanisms of plasticity. ${ }^{49}$ Although several age-related neurological changes have been identified during normal aging, these tend to be subtle compared with the ones observed in age-associated disorders, such as $\mathrm{AD}$ and Parkinson's disease (PD). ${ }^{49}$ Consequently, understanding age-related changes in cognition sets a background against which it is possible to assess the effects of the disease. ${ }^{49}$

For a long time, aging had been associated with neuronal loss independently of the brain region. ${ }^{50-53}$ However, the methods used in those studies question the accuracy of such results ${ }^{1,49}$ and subsequent studies have conclusively shown that the cell number is preserved in aging in several brain areas, including the hippocampus. ${ }^{54-59}$ These data highlight the differences between normal aging, characterized by structural preservation in the MTL, versus AD, which is associated with neuronal and synaptic loss in the MTL and in the hippocampus in particular. ${ }^{60}$

Although the total number of Schaffer collaterals-CA1 synapses is preserved across different age groups,${ }^{61}$ the amplitude of the Schaffer collaterals-induced field excitatory postsynaptic potentials (fEPSP) recorded in CA1 is reduced in aged memory-impaired animals. ${ }^{62-64}$ Furthermore, the PSD area of axospinous synapses is significantly reduced in aged learning-impaired rats ${ }^{65}$ (Fig. 3A). However, at the CA3-CA1 synapse, the size of the unitary EPSP remains constant during aging ${ }^{66}$ (Fig. 3A). Together, these data suggest that aging might not be associated with alterations in the strength of individual synaptic connections but instead with an increase in nonfunctional or silent synapses in the hippocampus ${ }^{49,67}$ (Fig. 3A).
Recently, transcriptomic analysis of the human aged brain revealed robust negative associations of genes encoding pre- and postsynaptic proteins with age, likely related to functional changes in synaptic integrity seen with aging (for a complete review see Burke and Barnes ${ }^{49,67}$ ). Interestingly, these changes occur across inhibitory and excitatory synapses and some of the strongest effects were observed in the hippocampus, consistent with the increased vulnerability of this structure to the aging process. ${ }^{68}$

Alterations in glutamate metabolism have also been described upon aging. In the hippocampus of mice and rats, the glutamate content in tissue samples decreases at 24-29 months, ${ }^{69-71}$ which may explain age-related changes in hippocampal neuron function during aging. However, basal extracellular concentrations of glutamate in aged rodents were reported to be either greater or lower, providing contradictory results,${ }^{71,72}$ and glutamate uptake, which terminates its action in the synapse, does not seem to be altered in aging. ${ }^{73-75}$ These results are difficult to reconcile, but this may be due to the fact that the concentration of glutamate sampled in most of these studies results from the release and uptake processes. Also, since most of these techniques cannot differentiate between neuronal and glial sources, the cellular origin of the glutamate released is still uncertain. ${ }^{76}$ In addition, age-related decreases in presynaptic release of glutamate may be compensated by changes in uptake and may also reflect alterations in the density of postsynaptic glutamate receptors.

In rodents, one of the well-characterized markers of physiological aging is an age-related decrease in action potential firing rates of CA1 pyramidal cells, with a concomitant decrease in the amplitude of the postburst after hyperpolarization responsible for spike frequency adaptation, ${ }^{77}$ reviewed by Wu et al.$^{78}$ Besides intrinsic properties, the excitatory synaptic transmission is altered during aging, being mainly studied in the hippocampus of old rats, and/or cortex of primates. ${ }^{78}$

Such alterations observed at individual synapses have a significant impact on synaptic plasticity. Age-associated memory deficits correlate with impairments in either LTP or LTD. ${ }^{28,79}$ In aged animals, LTP has been found to be reduced ${ }^{43,80-82}$ (Fig. 3B), not altered ${ }^{81,83-87}$ (Fig. 3B) or even strengthened. ${ }^{83,88-91}$ The latter is inconsistent with the classical correlation between increased LTP magnitude and better performance on hippocampaldependent memory tasks. Differences in the synaptic circuit that is being potentiated ${ }^{81}$ or in the stimulation protocol $^{49,83}$ may account for the observed discrepancies in LTP magnitude. Generally, age-associated alterations in LTP are only observed when weaker stimulus protocols are used, resulting in either an increase ${ }^{83,88,89,91}$ or in a decrease $^{79}$ of LTP (Fig. 3B).

Given the key role of AMPAR in LTP and LTD, synaptic plasticity alterations observed upon aging may be 


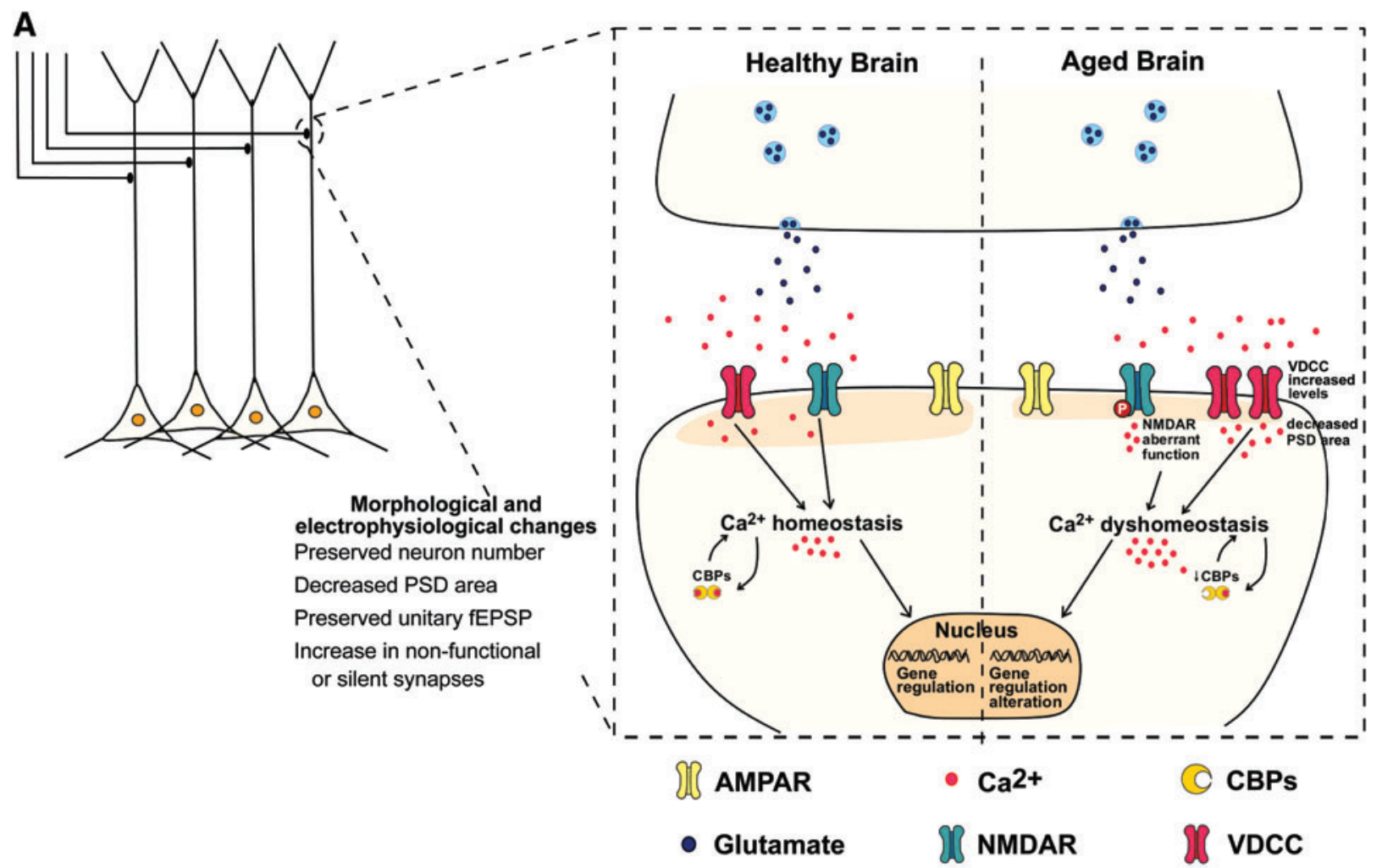

B

\section{Synaptic plasticity impairments}

Decrease in LTP upon TBS
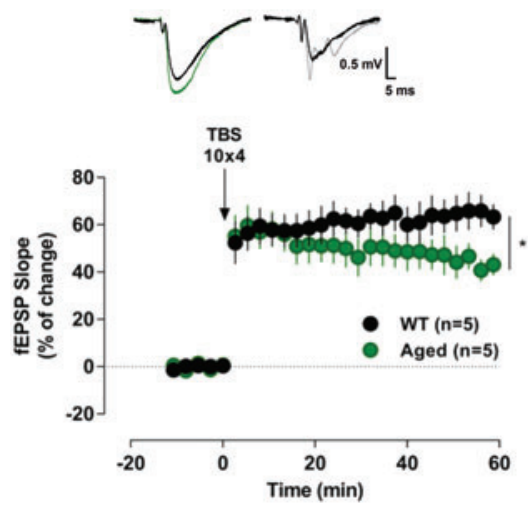

No alterations in LTP upon HFS
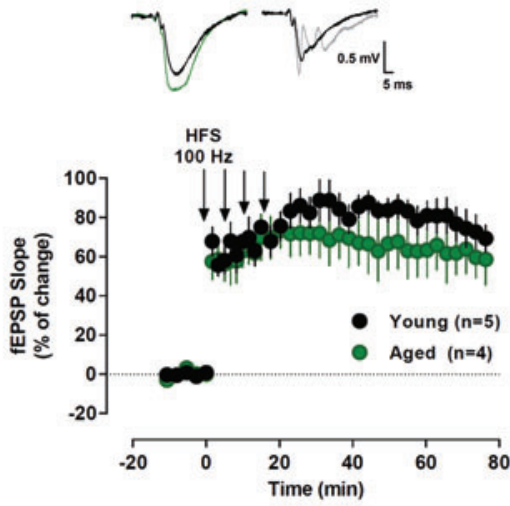

NMDAR

VDCC

FIG. 3. Morphological and synaptic alterations upon aging in the CA1 area of the hippocampus. (A) Morphological and electrophysiological impairments observed upon aging in CA1; increased VDCC and aberrant NMDA receptor function impair calcium homeostasis, further enhanced by a decrease in activity of calcium buffering proteins, driving alterations in gene regulation. (B) Examples of LTP and LTD time courses upon different stimulation protocols (TBS: 10 trains with 4 pulses at $100 \mathrm{~Hz}$, separated by 200 mseconds; HFS: 4 trains of 100 pulses at $100 \mathrm{~Hz}$, separated by 5 minutes; low-frequency stimulation: 3 trains of 1200 pulses at $2 \mathrm{~Hz}$, separated by 10 minutes); representative traces of fEPSPs before (black) and 50-60 minutes after (gray, green) LTD or LTP induction in young and aged rats. ${ }^{100}$ $* p<0.05$. CBPs, calcium-binding proteins; fEPSPs, field excitatory postsynaptic potentials; HFS, high-frequency stimulation; LFS, low-frequency stimulation; LTD, long-term depression; LTP, long-term potentiation; TBS, theta-burst stimulation. Color images are available online.

related with alterations in AMPAR expression and function, although very few studies have addressed that. Administration of AMPAR positive allosteric modulators restores age-related memory and synaptic potentiation deficits, ${ }^{92,93}$ suggesting an increase in silent
AMPAR rather than alterations in the expression of synaptic AMPAR. ${ }^{94}$

The transcription factor cAMP response elementbinding protein (CREB) has been shown to have fundamental roles in cognition and cellular excitability. ${ }^{95,96}$ 


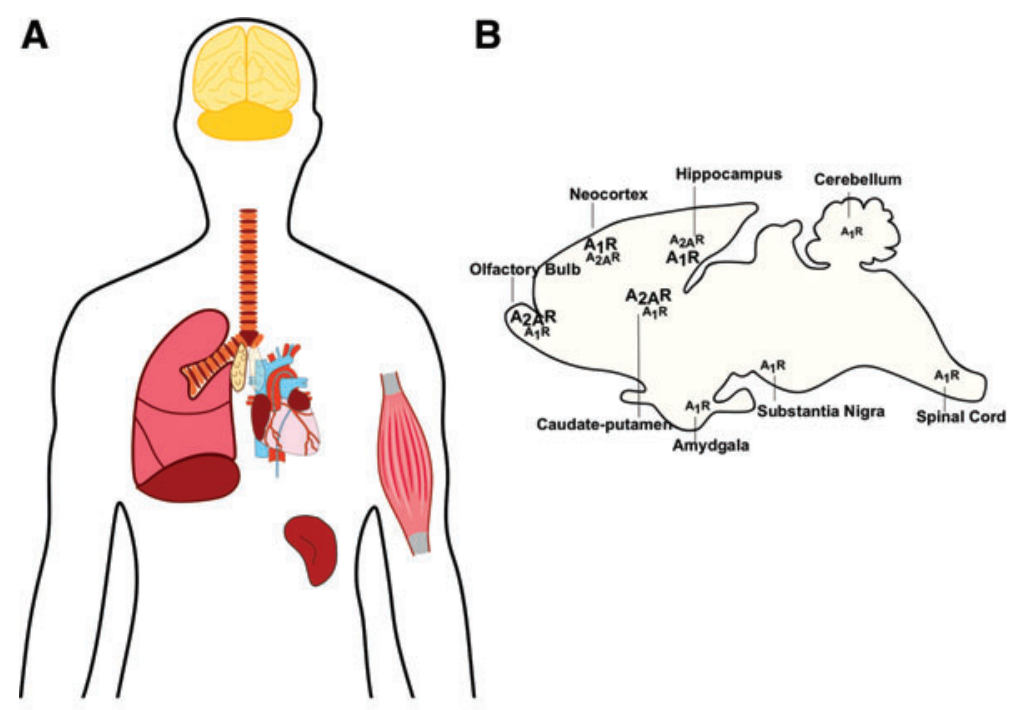

C

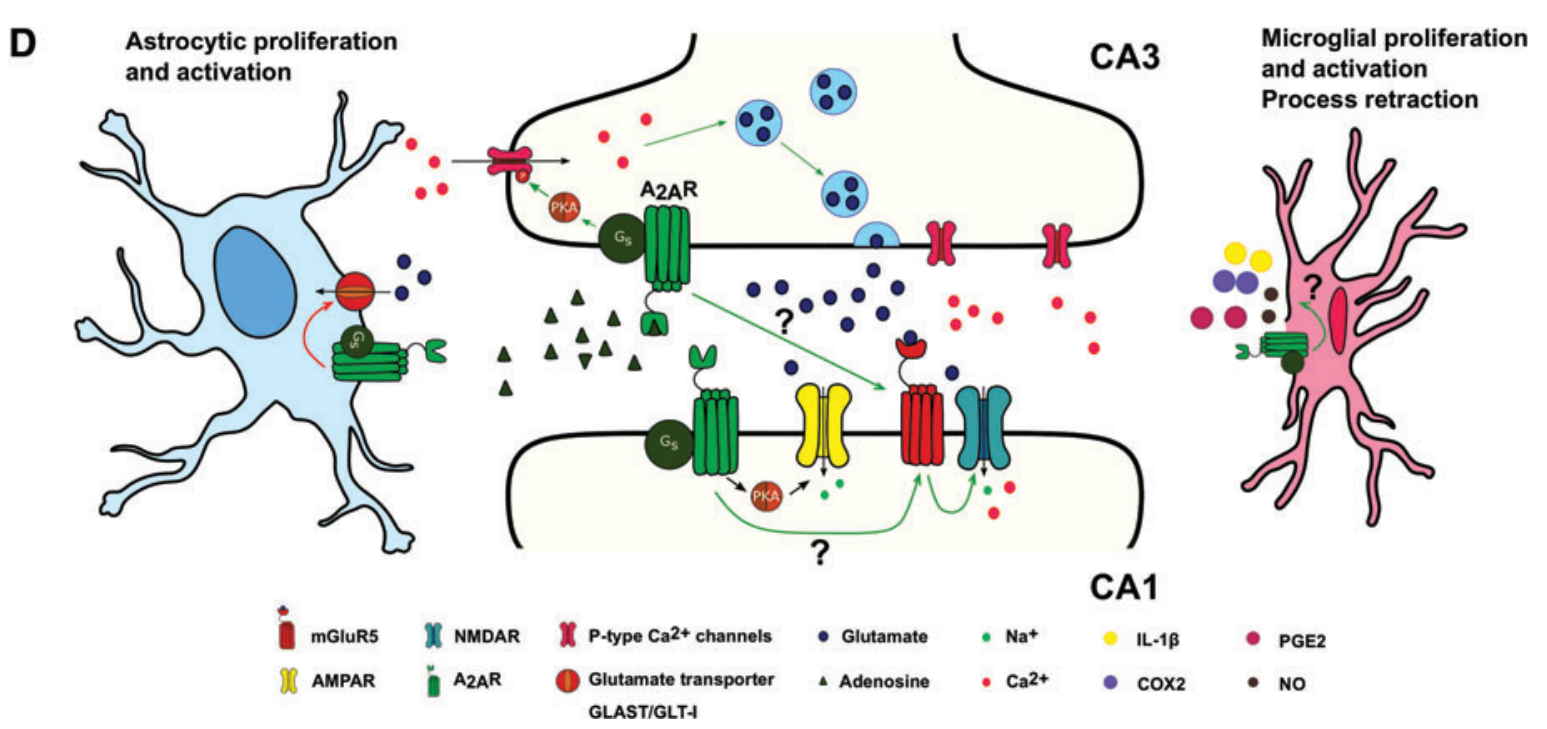

FIG. 4. Adenosine $A_{2 A} R$, distributed heterogeneously throughout the body, have important physiological functions in neurons, astrocytes, and microglia. (A) $\mathrm{A}_{2 \mathrm{~A}} \mathrm{R}$ are particularly expressed in the lungs, spleen, thymus, heart, blood vessels, muscle, and brain. ${ }^{267}$ (B) $\mathrm{A}_{2 \mathrm{~A}} \mathrm{R}$ are highly expressed in the olfactory bulb and striatum, whereas in the neocortex and hippocampus, they are present at residual levels. (C) Exogenous $\mathrm{A}_{2 \mathrm{~A}} \mathrm{R}$ activation induces a presynaptic enhancement of phasic GABAergic inputs from parvalbumin-expressing neurons to other GABAergic INs, driving disinhibition of PYR (green line), whereas $\mathrm{A}_{2 \mathrm{~A}} \mathrm{R}$ activation in PYR, presynaptically located, enhances glutamatergic inputs to other glutamatergic neurons (green line); $\mathrm{A}_{2 \mathrm{~A}} \mathrm{R}$ do not affect neither monosynaptic inhibitory inputs to excitatory neurons nor monosynaptic glutamatergic inputs to INs (black line). (D) $\mathrm{A}_{2 \mathrm{~A}} \mathrm{R}$, predominantly presynaptic, increase the release of glutamate in the hippocampus, possibly by inducing $\mathrm{Ca}^{2+}$ uptake and PKA-dependent $\mathrm{Ca}^{2+}$ currents through P-type $\mathrm{Ca}^{2+}$ channels in the presynaptic CA3 neurons that project onto the CA1 PYR. Postsynaptically, $\mathrm{A}_{2 \mathrm{~A}} \mathrm{R}$ facilitates AMPAR-evoked currents via PKA and increases mGluR5-dependent NMDAR phosphorylation and NMDAR-responses in CA1. However, pre- or postsynaptic localization of $\mathrm{A}_{2 \mathrm{~A}} \mathrm{R}$ and whether this is a direct or indirect interaction is lacking. In astrocytes, $\mathrm{A}_{2 \mathrm{~A}} \mathrm{R}$ activation induces astrocytic proliferation and activation and decreases glutamate uptake by controlling the expression levels of glutamate transporters subtypes GLT-I and GLAST. ${ }^{20,279,280}$ Microglial $\mathrm{A}_{2 \mathrm{~A}} \mathrm{R}$ drive proliferation and activation, process retraction and release of important immune mediators, particularly cyclooxygenase, PGE2, NO, and IL-1 $\beta \cdot{ }^{281-286} \mathrm{~A}_{2 \mathrm{~A}} \mathrm{R}, \mathrm{A}_{2 \mathrm{~A}}$ receptors; CA1 and CA3, cornu ammonis 1 and 3; CCK+, cholecystokinin-positive interneuron; COX2, cyclooxygenase 2; GABA, gamma-aminobutyric acid; IL-1 $\beta$, interleukin-1 $\beta$; IN, interneuron; NO, nitric oxide; PGE2, prostaglandin E2; PV+, parvalbumin-positive interneuron; PYR, pyramidal cell; SLM, stratum lacunosum-moleculare; SO, stratum oriens; SP, stratum pyramidale; SR, stratum radiatum. Color images are available online. 
The first study that identified an age-related CREB signaling dysfunction showed a reduction in LTP and performance in Barnes test that was ameliorated upon treatment with compounds that activate the cAMP/PKA pathway, possibly by increasing CREB activity. ${ }^{97}$ Levels of phosphorylated CREB (pCREB) are decreased in aged versus young animals after training in the Morris water maze, and strongly correlated with individual learning performance, whereas CREB expression itself does not change. ${ }^{98}$ These results suggest that alterations in activation rather than expression contribute to the age-related changes in cognition.

Some authors report increased susceptibility to LTD during aging ${ }^{87}$ whereas others fail to observe alterations in LTD magnitude in aged animals. ${ }^{84,99}$ These discrepancies can be explained by differences in animal strain, stimulation pattern, or $\mathrm{Ca}^{2+} / \mathrm{Mg}^{2+}$ ratio. Accordingly, paired-pulse LFS (PP-LFS) does not induce changes in LTD between young and aged animals, ${ }^{99}$ suggesting that different mechanisms may be involved in the induction of LTD by LFS and PP-LFS. Also, age-related differences in LTD induction could be rescued by manipulating the extracellular $\mathrm{Ca}^{2+} / \mathrm{Mg}^{2+}$ ratio. Indeed, the fact that induction of LTD is both a function of age and the levels of $\mathrm{Ca}^{2+}$ in the recording medium, strongly support an age-related $\mathrm{Ca}^{2+}$ dysregulation, and a shift in $\mathrm{Ca}^{2+}$-dependent induction mechanisms rather than in the LTD intrinsic capacity. ${ }^{84,99}$ Data produced by our group are consistent with this hypothesis, since we showed that aging is associated with a shift in the form of plasticity induced by a weak stimulus (LFS elicited LTP instead of LTD), as a consequence of increased NMDAR activation and $\mathrm{Ca}^{2+}$ influx ${ }^{100}$ (Fig. 3B).

It has been hypothesized that postsynaptic intracellular levels of $\mathrm{Ca}^{2+}$ are involved in setting a synaptic modification curve, which determines the probability that a synapse will be depressed or potentiated for a given pattern of input. ${ }^{61,101}$ Accordingly, since $\mathrm{Ca}^{2+}$ homeostasis is disrupted in aged animals (discussed further below), ${ }^{102,103}$ we can expect alterations in the probability for a given synapse to undergo potentiation or depression. All these observations support the calcium hypothesis of aging, which implicates raised intracellular $\mathrm{Ca}^{2+}$ as the major source of functional impairment and degeneration in aged neurons. ${ }^{104-106}$

To avoid excessive intracellular levels of calcium $\left(\left[\mathrm{Ca}^{2+}\right]_{\mathrm{i}}\right)$ elevations, neurons are equipped with complex machinery that permanently modulates the temporal and spatial patterns of $\mathrm{Ca}^{2+}$ signaling. ${ }^{107,108}$ Brief elevations of $\left[\mathrm{Ca}^{2+}\right]_{\mathrm{i}}$ are essential in controlling membrane excitability and modulating synaptic plasticity mechanisms, gene transcription, and other major cellular functions. ${ }^{107,108}$ However, long-lasting elevation of $\left[\mathrm{Ca}^{2+}\right]_{\mathrm{i}}$ triggers neurotoxic signaling pathways that ultimately will drive cell death. ${ }^{107,108}$

Several studies reported an age-associated increase in basal $\left[\mathrm{Ca}^{2+}\right]_{\mathrm{i}}$ levels ${ }^{109,110}$ as a result of increased voltage- dependent $\mathrm{Ca}^{2+}$ influx ${ }^{103,111,112}$ aberrant buffering ${ }^{113-115}$ (Fig. 3A), extrusion, ${ }^{110,116-118}$ and uptake capacity. ${ }^{119}$ Furthermore, given the key role of NMDAR in synaptic plasticity and memory, ${ }^{120}$ putative alterations in NMDAR may also account for $\mathrm{Ca}^{2+}$ dysregulation.

In aged CA1 pyramidal neurons, there is an increased duration of NMDAR-mediated responses. ${ }^{121}$ Consistent with this hypothesis, aged animals display an NMDAR overactivation upon glutamate or glycine stimulation, despite a decrease in the density of these receptors ${ }^{122}$ (Fig. 3A). However, such alteration in NMDAR-mediated responses may be due to the previously described increase in nonfunctional synapses with aging. The fact that there is an increased binding of the NMDAR antagonist MK-801 in animals with learning and retention deficits $^{123,124}$ suggest that an increase in NMDAR channel open-time happens as a compensatory mechanism for the apparent decrease in receptor number, ${ }^{125}$ since MK-801 only binds open channels.

The age-associated synaptic dysfunction can also be a consequence of alterations in astrocytes and microglia, as the aging process has also been described as inflammaging, a status of chronic inflammation that contributes to the pathogenesis of neurodegenerative diseases. ${ }^{126}$ Although the number of astrocytes remains unaffected ${ }^{127-129}$ in aged humans, in rats there seems to be an increase in the astrocytic size, described in the hippocampus. ${ }^{129}$ In mice, age decreases the expression of ionotropic and purinergic receptors ${ }^{130}$ and neurotransmitter-induced $\mathrm{Ca}^{2+}$ signaling. ${ }^{131}$ Importantly, age is also associated with reduced expression of water channels (aquaporins 4) in astroglial perivascular processes and markedly diminished clearance of the brain parenchyma through the glymphatic pathway, ${ }^{132}$ a key process in the prevention of the accumulation of misfolded protein aggregates.

Microglia alterations upon aging have also been described in several species. Age-dependent microglia activation was found in aged rodents, nonhuman primates, and humans, ${ }^{133-135}$ characterized by increased expression of MHCII, CD68, TLRs, and proinflammatory cytokines such as TNF $\alpha$, interleukin-1 $\beta$ (IL-1 $\beta$ ), and IL-6. ${ }^{136-140}$ However, other studies unravel a microglial dystrophic/ senescent phenotype in aged individuals, ${ }^{141,142}$ thus supporting the hypothesis that, rather than induction of microglial activation, progressive microglial degeneration and loss of microglial neuroprotection are associated with aging and further contribute to the onset and progression of neurodegenerative diseases such as $\mathrm{AD}$.

\section{The Modulation of Aged Synapse by Adenosine $A_{2 A}$ Receptors}

Adenosine influences many functions in the CNS. Besides the neuromodulatory actions, adenosine acts as a fine-tuner of synaptic communication, as it is a relevant player in neuron-glia communication and can affect the 
release and action of many neurotransmitters and other neuromodulators. ${ }^{143-147}$ Accordingly, the neuromodulatory role of adenosine is mediated by a balance between the inhibitory and excitatory actions via $A_{1} R$ (usually coupled to adenylate cyclase inhibitory proteins, Gi/Go) and $A_{2 A}$ receptors $\left(A_{2 A} R\right.$; coupled to adenylate cyclase inhibitory proteins $\mathrm{Gs}$ ), the most relevant adenosine receptors in the CNS. ${ }^{148}$ The effects of adenosine depend on the receptors expression pattern and signaling, the brain region, and pathophysiological condition. $\mathrm{A}_{1} \mathrm{R}$ are widely distributed, being more abundant in the cortex, cerebellum, and hippocampus. ${ }^{149}$ On the opposite, $\mathrm{A}_{2 \mathrm{~A}} \mathrm{R}$ display a more restricted expression pattern: $\mathrm{A}_{2 \mathrm{~A}} \mathrm{R}$ are highly expressed in the olfactory bulb and striatum, ${ }^{150}$ whereas in the neocortex and hippocampus they are present at residual levels ${ }^{151,152}$ (Fig. 4A, B). $\mathrm{A}_{2 \mathrm{~A}} \mathrm{R}$ are mostly located in glutamatergic synapses, ${ }^{153}$ although they have been shown in other synapses, such as GABAergic ${ }^{146,154,155}$ (Fig. 4C), dopaminergic, ${ }^{156,157}$ cholinergic, ${ }^{158,159}$ serotoninergic, ${ }^{160,161}$ or noradrenergic synapses. ${ }^{162}$

Adenosine levels are tightly controlled by a complex machinery of enzymes. However, in the aged rat, the activity of the enzymes that form adenosine from ATP (5'-nucleotidases) and terminate adenosine actions by phosphorylation to AMP (adenosine kinase, ADK) have been reported to be increased, possibly leading to the reported elevation of adenosine levels in the brain $^{163-165}$ and interference with the transmethylation pathway. This can at least explain the decrease in global DNA methylation observed upon aging.

Glucose metabolism impairment or mitochondria dysfunction, common features observed in aging, and AD may lead to the reduction of cellular ATP levels and trigger the process of ATP production from adenosine. Accordingly, ATP levels are significantly reduced in the brain of APPswe/PS1dE9 mice ${ }^{166}$ and can lead to a reduction in adenosine levels and mitochondria dysfunction. ${ }^{167-169}$ Adenosine acts as a cellular sensor of intracellular ATP levels: elevation of adenosine in response to falling ATP levels has cytoprotective effects, whereas when decoupled from ATP levels can be cytotoxic to the cell. ${ }^{168}$ In $\mathrm{AD}$, adenosine levels have been categorized according to AD stage. ${ }^{167}$ Alonso-Andrés et al. showed that adenosine is the most affected purine in $\mathrm{AD}$, being decreased since early stage,${ }^{167}$ possibly as a result of a decrease in $5^{\prime}$-nucleotidases. ${ }^{170}$ Adenosine augmentation has been found beneficial in multiple neurological disorders, including AD. ${ }^{171,172}$ However, further comprehension of the mechanism and the putative effects on adenosine receptors and downstream signaling pathways are crucial at this stage.

In glutamatergic synapses, under physiological conditions and basal activity, adenosine preferentially stimulates $\mathrm{A}_{1} \mathrm{R}$, leading to inhibition of glutamatergic synaptic transmission in the hippocampus. ${ }^{173,174}$ Adenosine can also activate $\mathrm{A}_{2 \mathrm{~A}} \mathrm{R}$, which decreases $\mathrm{A}_{1} \mathrm{R}$ binding and thus an inhibition of $\mathrm{A}_{1} \mathrm{R}$ actions. ${ }^{143}$ Several studies addressed the cellular mechanisms triggered by $\mathrm{A}_{2 \mathrm{~A}} \mathrm{R}$ activation, either by modulating the adenosine endogenous levels pharmacologically and/or by applying its specific agonist, such as CGS21680, allowing a comprehensive knowledge of its action, as follows. $A_{2 A} R$, predominantly presynaptic, ${ }^{153}$ increase the release of glutamate in the hippocampus, ${ }^{143,175}$ possibly by inducing $\mathrm{Ca}^{2+}$ entry ${ }^{176}$ and PKA-dependent $\mathrm{Ca}^{2+}$ currents through P-type $\mathrm{Ca}^{2+}$ channels in the presynaptic CA3 neurons ${ }^{177}$ that project onto the CA1 pyramidal cells (Fig. 4C, D). Postsynaptically, $\mathrm{A}_{2 \mathrm{~A}} \mathrm{R}$ facilitates AMPAR-evoked currents via PKA in CA1 pyramidal neurons, independent of NMDAR and $\mathrm{GABA}_{\mathrm{A}}$ receptor activation or synaptic activity ${ }^{178}$ (Fig. 4D). In mossy fiber synapses, $\mathrm{A}_{2 \mathrm{~A}} \mathrm{R}$ activation along the extrasynaptic plasma membrane of CA3 dendritic spines is essential for LTP of NMDAREPSCs. ${ }^{179}$ This LTP is dependent on postsynaptic $\mathrm{Ca}^{2+}$ rise, NMDAR, mGluR5, and Src tyrosine kinases family activation. ${ }^{179}$ This was the first article that provided electrophysiological evidence and biological relevance for a $\mathrm{A}_{2 \mathrm{~A}} \mathrm{R}-\mathrm{mGluR5}$-NMDAR interaction.

Other studies also hinted at a possible $\mathrm{A}_{2 \mathrm{~A}} \mathrm{R}-\mathrm{NMDAR}$ interaction, since $\mathrm{A}_{2 \mathrm{~A}} \mathrm{R}$ activation increases mGluR5dependent NMDAR phosphorylation and NMDARresponses in CA1. ${ }^{180-182}$ However, the exact pre- or postsynaptic localization of $\mathrm{A}_{2 \mathrm{~A}} \mathrm{R}$ and whether this is a direct or indirect interaction is yet to be clarified (Fig. 4D). Also, $\mathrm{A}_{2 \mathrm{~A}} \mathrm{R}$ seem to act as fine-tuners of other neuromodulatory systems, since $\mathrm{A}_{2 \mathrm{~A}} \mathrm{R}$ activation is required to observe synaptic effects of neuropeptides ${ }^{145,183-185}$ or growth factors, namely for the facilitatory actions of brain-derived neurotrophic factor (BDNF) on synaptic transmission ${ }^{145,185,186}$ and on LTP. ${ }^{187}$ Furthermore, $\mathrm{A}_{2 \mathrm{~A}} \mathrm{R}$ activation decreases the efficiency of presynaptic inhibitory systems, namely cannabinoid CB1 receptors. ${ }^{188,189}$ However, whether these effects are mediated by neuronal or glial $\mathrm{A}_{2 \mathrm{~A}} \mathrm{R}$ is still a matter of debate. As indicated, some of the above mentioned effects of $\mathrm{A}_{2 \mathrm{~A}} \mathrm{R}$ on glutamate transmission were observed upon exogenous activation with agonists, such as CGS 21630. ${ }^{143,175,176,178}$ However, this may not replicate exactly the endogenous activation-mediated actions.

The comprehensive characterization of the full $\mathrm{A}_{2 \mathrm{~A}} \mathrm{R}$ $\mathrm{KO}$ mice allowed to study the role of these receptors under physiological conditions. These mice display reduced exploratory activity, increased anxiety, and aggressiveness. ${ }^{190}$ Furthermore, mice lacking $\mathrm{A}_{2 \mathrm{~A}} \mathrm{R}$ show improved spatial recognition memory ${ }^{191}$ and preferential enhancement of working memory. ${ }^{192}$

However, chronic or acute blockade of $\mathrm{A}_{2 \mathrm{~A}} \mathrm{R}$ does not alter neither basal glutamate transmission nor the magnitude of LTP or LTD, ${ }^{100,193,194}$ and knocking-out the $\mathrm{A}_{2 \mathrm{~A}} \mathrm{R}$ does not impact on LTD, ${ }^{195}$ strongly suggesting a lack of $\mathrm{A}_{2 \mathrm{~A}} \mathrm{R}$ constitutive activation in young glutamatergic synapses. This idea is further supported by the 
absence of effect of $\mathrm{A}_{2 \mathrm{~A}} \mathrm{R}$ chronic blockade or genetic deletion in the Morris water maze and Y-maze tests. ${ }^{100,193,195,196}$ A question might be raised: How could $\mathrm{A}_{2 \mathrm{~A}} \mathrm{R}$ behavioral phenotypes, which suggest some memory processes, are upon the control of $\mathrm{A}_{2 \mathrm{~A}} \mathrm{R}$, be reconciled with the absence of an $\mathrm{A}_{2 \mathrm{~A}} \mathrm{R}$ constitutive activation in young glutamatergic synapses? Novel mice models with neuronal circuitry/cell type selective $\mathrm{A}_{2 \mathrm{~A}} \mathrm{R}$ deletion will allow to dissect which synapses/cells are implicated in the mechanisms underlying these memory phenotypes, excluding artefacts/compensations due to full genetic ablation of the receptor.

$\mathrm{A}_{2 \mathrm{~A}} \mathrm{R}$ expression and signaling is profoundly altered in the hippocampus upon aging. $\mathrm{A}_{2 \mathrm{~A}} \mathrm{R}$ density and coupling to $G$ protein is increased, ${ }^{100,144,164,197-199}$ probably enhancing the action of this receptor to facilitate neurotransmitters release in glutamatergic synapses by a presynaptic mechanism. ${ }^{197}$ However, whether this increase in $\mathrm{G}$ protein coupling is due to receptors covalent modifications or other alterations is not known yet. ${ }^{144,197}$ This age-related enhanced $\mathrm{A}_{2 \mathrm{~A}} \mathrm{R}$-mediated facilitation of synaptic transmission is dependent on PKA and is associated to an increase in cAMP accumulation. ${ }^{144}$ Other authors also observed an enhanced role of $\mathrm{A}_{2 \mathrm{~A}} \mathrm{R}$ in the modulation of LTP, since $\mathrm{A}_{2 \mathrm{~A}} \mathrm{R}$ antagonist SCH58261-induced decrease in LTP is increased in aged animals, ${ }^{199}$ either due to alterations in $\mathrm{A}_{2 \mathrm{~A}} \mathrm{R}$ or changes in dynamic range of LTP.

Although at physiological levels, the expression of $\mathrm{A}_{2 \mathrm{~A}} \mathrm{R}$ in the hippocampus seems to be protective, by fine-tuning the function of other protein-partners, such as the BDNF-TrKB signaling, ${ }^{145,185-187}$ the fact is that $\mathrm{A}_{2 \mathrm{~A}} \mathrm{R}$ overexpression, in a similar magnitude, to the one observed in human aging, is deleterious, as it is sufficient to trigger synaptic and cognitive deficits. This effect involves a mGluR5-dependent NMDAR overactivation, leading to enhanced $\mathrm{Ca}^{2+}$ influx, ${ }^{100}$ which recapitulates the main synaptic alterations observed upon aging (see previous section). The way mGluR5 activates NMDAR is still unclear, and several alternatives are plausible. mGluR5 are linked to NMDAR via a Homer/Shank/ PSD-95 complex of proteins ${ }^{200-202}$ and several studies have found that mGluR5 enhances NMDAR currents through a $\mathrm{PKC} / \mathrm{IP}_{3}$-calcium-dependent mechanism. ${ }^{203-206}$ Our group provided evidence that $\mathrm{A}_{2 \mathrm{~A}} \mathrm{R}$ activation mediates mGluR5-dependent NMDAR phosphorylation of the residue Tyr1472 of GluN2B subunit by Fyn kinases activation in a PD model ${ }^{193}$ (Fig. 5), as previously reported by others in physiological conditions. ${ }^{181}$

Whether mGluR5 activates NMDAR by multiple pathways in the same synapses or if each pathway is regionspecific is still unclear. Another important target of the kinase activity of Fyn is tau, and this interaction was already shown to be important in the AD-related tau hyperphosphorylation $^{207,208}$ (Fig. 5). Physiologically, Fyn regulates NMDAR activity. ${ }^{209,210}$ On the contrary, tauFyn interaction leads to Fyn accumulation in the soma, preventing Fyn from migrating to postsynaptic site, ${ }^{208}$ possibly leading to aberrant NMDAR signaling observed in aging and $\mathrm{AD}$.
FIG. 5. The aging synapse: in the CA1 area of the hippocampus, $\mathrm{A}_{2 \mathrm{~A}} \mathrm{R}$ increased levels are associated with postsynaptic impairments, such as a mGluR5-dependent NMDAR activation, possibly through Fyn Kinases. NMDAR aberrant activation and VDCC increased expression trigger an increase in $\mathrm{Ca}^{2+}$ influx. Associated with a dysfunction of CBPs, this mechanism shifts $\mathrm{Ca}^{2+}$ dependent induction mechanism, which explains the alterations observed in LTP and LTD upon aging. $\mathrm{Ca}^{2+}$ dyshomeostasis and the associated synaptic plasticity shift impair gene regulation, further exacerbating synaptic dysfunction. Color images are available online.

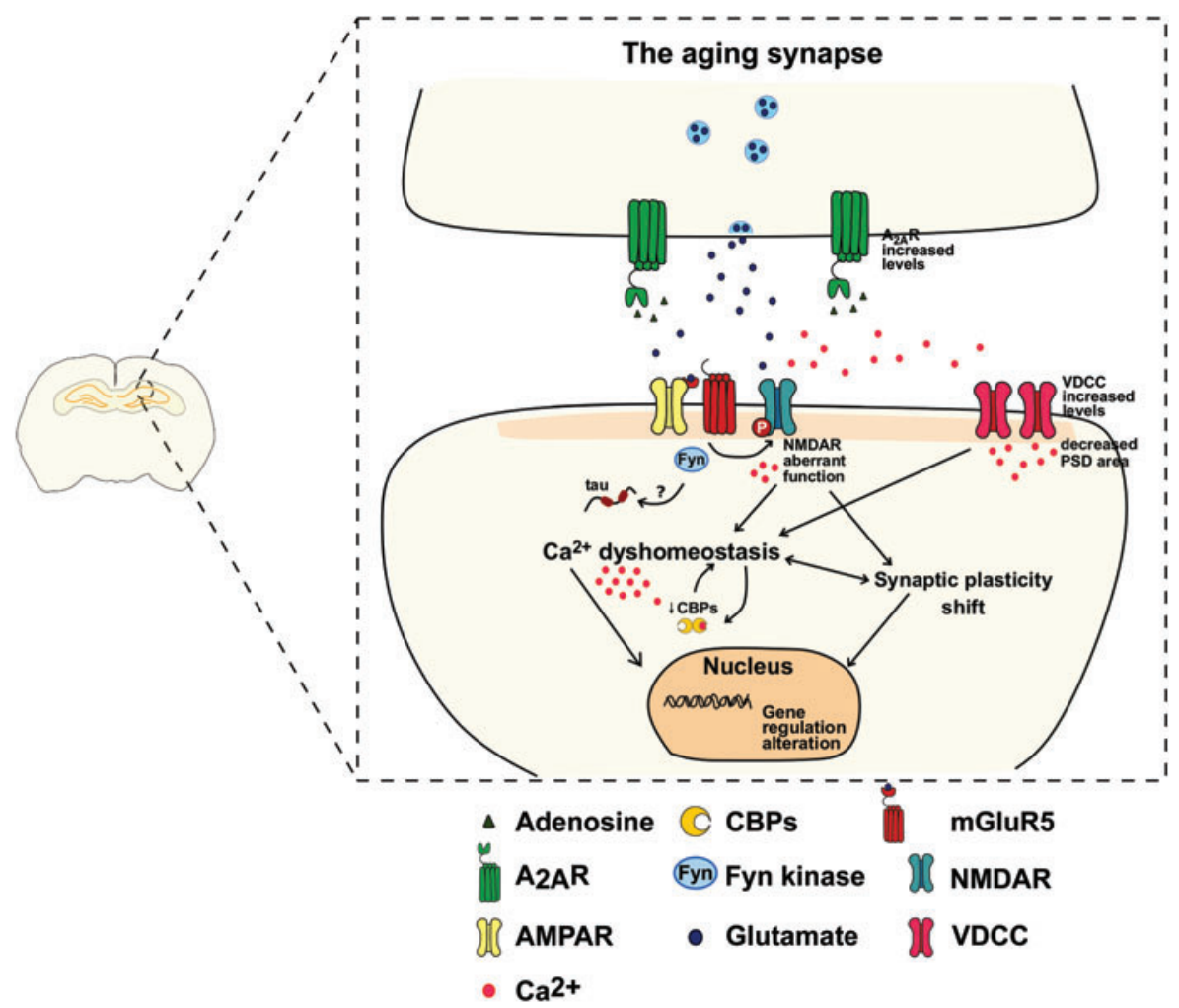


One of the hypothetic mechanisms for these ageassociated alterations in $\mathrm{A}_{2 \mathrm{~A}} \mathrm{R}$ is a shift in dimerization process. In physiological conditions, $\mathrm{A}_{1} \mathrm{R}$ and $\mathrm{A}_{2 \mathrm{~A}} \mathrm{R}$ are coexpressed in CA1 pyramidal neurons ${ }^{153}$ and $\mathrm{A}_{2 \mathrm{~A}} \mathrm{R}$ activation decreases presynaptic $A_{1} R$ binding and functional responses in aged animals via PKC. ${ }^{211}$ Importantly, attenuation of $\mathrm{A}_{1} \mathrm{R}$ responses elicited by $\mathrm{A}_{2 \mathrm{~A}} \mathrm{R}$ activation is larger in amplitude than the direct facilitatory effect of $\mathrm{A}_{2 \mathrm{~A}} \mathrm{R}$ agonist CGS21680, suggesting that the main role of $A_{2 A} R$ in young animals is to modulate $A_{1} R$ responses rather than to directly facilitate neuronal excitability. ${ }^{211}$ These age-associated $\mathrm{A}_{1} \mathrm{R}-\mathrm{A}_{2 \mathrm{~A}} \mathrm{R}$ cross talk loss and amplification of $\mathrm{A}_{2 \mathrm{~A}} \mathrm{R}$-mediated responses suggest alterations in the organization and relative densities of GPCR and intracellular pathways, namely change in nature of the interaction, that is, homodimer $\mathrm{A}_{2 \mathrm{~A}} \mathrm{R}-\mathrm{A}_{2 \mathrm{~A}} \mathrm{R}$ rather than heterodimer $\mathrm{A}_{2 \mathrm{~A}} \mathrm{R}-\mathrm{A}_{1} \mathrm{R}$ formation.

In the striatum, $A_{2 A} R$ and $A_{1} R$ form heteromers and, under physiological conditions, adenosine preferentially activate $\mathrm{A}_{1} \mathrm{R},{ }^{212,213}$ which controls glutamatergic neurotransmission, namely by a decrease in NMDAR-mediated responses. $^{214,215}$ If a stoichiometric upsurge favoring nonheteromer forming $\mathrm{A}_{2 \mathrm{~A}} \mathrm{Rs}$ results in Gs-dominant signaling, ${ }^{177}$ then an $\mathrm{A}_{2 \mathrm{~A}} \mathrm{R}$ assembly switch could be the primary event driving this pathological glutamate output. However, due to the physiological residual levels of $\mathrm{A}_{2 \mathrm{~A}} \mathrm{R}$ in the hippocampus and lack of experimental tools and techniques, the question of $A_{1} R-A_{2 A} R$ heterodimerization in glutamatergic synapses or a putative age-associated dimerization switch has not been yet solved.

\section{Alzheimer's disease}

An increase in hippocampal $\mathrm{A}_{2 \mathrm{~A}} \mathrm{R}$ expression is also observed in several other pathologies in humans, in which there is a clear correlation of hippocampal $\mathrm{A}_{2 \mathrm{~A}} \mathrm{R}$ upregulation with cognitive deficits, such as in Alzheimer's ${ }^{100,217}$ and Pick's disease. ${ }^{218}$ Interestingly, adenosine levels are significantly increased in parietal and temporal cortices from the early stages of AD postmortem brains, alterations that occur independently of neurofibrillary tangles and $\beta$-amyloid plaques, ${ }^{167}$ which would further enhance $\mathrm{A}_{2 \mathrm{~A}} \mathrm{R}$ activation and signaling.

Neuronal and astrocytic primary cultures incubated with $\mathrm{A} \beta$-oligomers point out the therapeutic effect of $\mathrm{A}_{2 \mathrm{~A}} \mathrm{R}$ blockade. Either caffeine (nonselective adenosine receptor antagonist) or ZM241385 (selective $\mathrm{A}_{2 \mathrm{~A}} \mathrm{R}$ antagonist) prevented neuronal loss caused by incubation of $\mathrm{A} \beta_{25-35}$ in rat cultured cerebellar granule neurons. ${ }^{219}$ In cortical primary astrocytes, treatment with SCH58261 rescues the decreased expression of glutamate transporters GLAST and GLT-1 and increased GFAP immunoreactivity caused by incubation with $\mathrm{A} \beta_{1-42}$, suggesting that astrocytic $\mathrm{A}_{2 \mathrm{~A}} \mathrm{R}$ can therapeutically modulate the ADassociated increased levels of extracellular glutamate and astrocytic reactivity. ${ }^{220}$ Importantly, these effects seem to be dependent of $\mathrm{A}_{2 \mathrm{~A}} \mathrm{R}$ since $\mathrm{A} \beta_{1-42}$ can no longer induce such astrocytic alterations in global- $A_{2 A} R-K^{220}$ and, in this case, we cannot rule out neuronal $\mathrm{A}_{2 \mathrm{~A}} \mathrm{R}$ contribution in this $\mathrm{A} \beta$-induced astrocytic dysfunction.

There is also compelling evidence from animal models of an aberrant $\mathrm{A}_{2 \mathrm{~A}} \mathrm{R}$ expression and signaling in $\mathrm{AD}$. Intercerebroventricular injection of $\mathrm{A} \beta_{1-42}$ in mice and rats induces loss of nerve terminal markers and memory impairments, which were rescued upon either pharmacological blockade or genetic inactivation. ${ }^{221}$ Neuronal $\mathrm{A}_{2 \mathrm{~A}} \mathrm{R}$ play an important role in this synaptic dysfunction, since SCH58261 also has a beneficial effect in preventing loss of synaptic markers in cultured hippocampal neurons incubated with the same $\mathrm{A} \beta$ fragment. ${ }^{221}$ Opposite to what is described, ${ }^{211} \mathrm{~A}_{2 \mathrm{~A}} \mathrm{R}$-mediated effects are dependent on p38 mitogen-activated protein kinase pathway and independent of $\mathrm{cAMP} / \mathrm{PKA},{ }^{221}$ suggesting that $\mathrm{A}_{2 \mathrm{~A}} \mathrm{R}$ may activate parallel and independent pathways that ultimately converge to induce synaptotoxicity.

The $\mathrm{A}_{2 \mathrm{~A}} \mathrm{R}$-mediated effects on synaptic dysfunction are particularly visible in a mouse model of tauopathy, ThyTau22. $A_{2 A} R$ deletion is sufficient to prevent memory defects, LTD impairments, and Tau hyperphosphorylation observed in these animals. ${ }^{195}$ Importantly, chronic treatment with the $\mathrm{A}_{2 \mathrm{~A}} \mathrm{R}$ antagonist MSX-3 rescued hippocampal-dependent memory even after onset of the pathology, ${ }^{195}$ further emphasizing the central role of $\mathrm{A}_{2 \mathrm{~A}} \mathrm{R}$ in synaptic and memory dysfunction. Whether this is an astrocytic or neuronal $\mathrm{A}_{2 \mathrm{~A}} \mathrm{R}$ role remains inconclusive. The fact that Thy-Tau22- $\mathrm{A}_{2 \mathrm{~A}} \mathrm{R}^{-/-}$mice exhibit decreased astrogliosis further supports the hypothesis of an astrocytic contribution to the $\mathrm{A}_{2 \mathrm{~A}} \mathrm{R}$-mediated deficits, but does not discard a putative neuronal role. Consistent with this view, astrocytic $\mathrm{A}_{2 \mathrm{~A}} \mathrm{R}$ overexpression in $\mathrm{AD}$ human samples was assessed by correlation between $\mathrm{A}_{2 \mathrm{~A}} \mathrm{R}$-encoding gene (ADORA2A) and GFAP messenger RNA (mRNA) levels and immunohistochemistry, ${ }^{217}$ although neuronal expression was not addressed. Chemogenetic activation of astrocytic Gs-coupled signaling increases cAMP and CREB and reduces long-term memory in mice ${ }^{217}$ and conditional ablation of $\mathrm{A}_{2 \mathrm{~A}} \mathrm{R}$ in astrocytes reduces memory deficits in 15-18 m.o. hAPP animals. ${ }^{217}$

In APP/PS1 animals (double transgenic mice expressing a chimeric mouse/human amyloid precursor protein [Mo/HuAPP695swe] and a mutant human presenilin 1 [PS1-dE9]), an AD mouse model, lack of associative NMDAR-independent LTP in an early stage and cognitive impairments in the Y-maze test ${ }^{222}$ are rescued upon pharmacological and viral $\mathrm{A}_{2 \mathrm{~A}} \mathrm{R}$ blockade in neurons. ${ }^{222}$ Interestingly, either $\mathrm{A}_{2 \mathrm{~A}} \mathrm{R}$ or mGluR5 blockade rescues LTP back to wildtype (WT) levels, suggesting that $\mathrm{A}_{2 \mathrm{~A}} \mathrm{R}$ and mGluR5 operate through a common pathway to impair LTP, as we also observed. ${ }^{100,193}$ The crucial neuronal $\mathrm{A}_{2 \mathrm{~A}} \mathrm{R}$ role on synaptic dysfunction was further highlighted by us and others, since neuronal 
$\mathrm{A}_{2 \mathrm{~A}} \mathrm{R}$ overexpression is sufficient to trigger CREBdependent synaptic and memory dysfunction. ${ }^{100,223}$ We found that aged animals could be divided into two subsets: age-impaired animals, which performed worse than young rats in the Y-maze test, revealing no preference for the novel arm, and age-unimpaired animals performed within the range of young rats. Age-impaired animals seem to be distinguished by an LTD-to-LTP shift, whereas age-unimpaired animals could be distinguished by their lack of response to LFS. Consistent with an enhanced role of $\mathrm{A}_{2 \mathrm{~A}} \mathrm{R}$ upon aging, SCH 58261 decreased basal transmission in hippocampal slices of aged animals, while no effect was observed in young animals. A tendency toward an increased effect of SCH 58261 in age-impaired subset, when compared with age-unimpaired animals, suggests an increased $\mathrm{A}_{2 \mathrm{~A}} \mathrm{R}$ activation in age-impaired animals. ${ }^{100}$

More specifically, a 3-week treatment with the selective $\mathrm{A}_{2 \mathrm{~A}} \mathrm{R}$ antagonist KW6002 restored memory impairments. ${ }^{100}$ The fact that an acute $\mathrm{A}_{2 \mathrm{~A}} \mathrm{R}$ blockade is sufficient to rescue the LTD-to-LTP shift favors the hypothesis that $\mathrm{A}_{2 \mathrm{~A}} \mathrm{R}$ blockade reestablishes the physiological signaling of adenosine, rather than the receptor expression, which is unlikely to occur at such a short time frame. Accordingly, we have prior data showing that chronic KW6002 treatment rescues cognitive and synaptic impairments induced by stress, without altering $\mathrm{A}_{2 \mathrm{~A}} \mathrm{R}$ levels. ${ }^{224}$

Also, $\mathrm{A}_{2 \mathrm{~A}} \mathrm{R}$ activation increases $\mathrm{Ca}^{2+}$ influx via mGluR5 and NMDAR in primary neuronal cultures, discarding any major $\mathrm{A}_{2 \mathrm{~A}} \mathrm{R}$ astrocytic contribution. ${ }^{100}$ Furthermore, we observed neuron-specific $\mathrm{A}_{2 \mathrm{~A}} \mathrm{R}$ staining and aged humans and $\mathrm{AD}$ patients' hippocampus, ${ }^{100}$ consistent with previous data, in which single-cell polymerase chain reaction of laser-dissected cells of young rats revealed no $\mathrm{A}_{2 \mathrm{~A}} \mathrm{R}$ transcripts in GFAP positive cells. ${ }^{153}$ Plus, in some brain pathological conditions, characterized by astrogliosis or increases in excitability, such as mesial temporal lobe epilepsy, there is a profound increase in $A_{2 A} R$ in astrocytes that is not related with $A \beta$ or any other features of neurodegenerative disease. ${ }^{225}$ Interestingly, a recent study showed that deletion of $\mathrm{A}_{2 \mathrm{~A}} \mathrm{R}$ selectively in forebrain neurons prevented convulsions-induced neurodegeneration (decreased synaptic plasticity, loss of synaptic markers, and neuronal loss) in a kainate model of temporal lobe epilepsy. ${ }^{226}$ Altogether, these data strongly suggest that it is a synergism of astrocytic and neuronal $\mathrm{A}_{2 \mathrm{~A}} \mathrm{R}$-mediated effects that defines the robust ability to control synaptic and memory dysfunction: synaptic dysfunction in aging and early $\mathrm{AD}$ may be driven predominantly by a neuronal $\mathrm{A}_{2 \mathrm{~A}} \mathrm{R}$ progressive dysfunction, whereas at later Braak stages of $\mathrm{AD}$, astrocytic $\mathrm{AD}$ and inflammation may become more relevant.

Most importantly, this $\mathrm{A}_{2 \mathrm{~A}} \mathrm{R}$ pathological role was also observed in humans: AD patients exhibit an increase in $\mathrm{A}_{2 \mathrm{~A}} \mathrm{R}$ expression ${ }^{100,227}$ and a single nucleotide poly- morphism (SNP) in ADORA2A was recently associated with episodic memory performance, hippocampal volume, and total tau in cerebrospinal fluid (CSF) in mild cognitive impairment $(\mathrm{MCI})$ and $\mathrm{AD}$ patients, ${ }^{228}$ suggesting that this variation may affect $\mathrm{A}_{2 \mathrm{~A}} \mathrm{R}$ production. However, this still needs to be confirmed in future studies. Also, multiple prospective and retrospective studies emphasize the role of caffeine, a nonselective adenosine receptor antagonist, in slowing down cognitive decline in aged population and reducing the risk of developing $\mathrm{AD}$.

\section{Regulation of ADORA2A gene expression}

An important question yet to be clarified is the mechanism by which $\mathrm{A}_{2 \mathrm{~A}} \mathrm{R}$ expression increases upon aging and $\mathrm{AD}$ on the hippocampus. Given the role of $\mathrm{A}_{2 \mathrm{~A}} \mathrm{R}$ in multiple brain regions, the regulation of its expression and signaling has received great attention. A $4.8 \mathrm{~kb}$ promoter-proximal DNA fragment in the ADORA2A confers selective expression in the CNS, but does not explain the strong expression observed in the striatum. ${ }^{229}$ These results suggest that the $A_{2 \mathrm{~A}} \mathrm{R}$ expression is also controlled by other (epi)genetic factors that regulate the expression in each brain structure.

In fact, the coding for the $A_{2 A} R$ exists in two exons interrupted by one intron and has multiple promoters that lead to the production of various $\mathrm{A}_{2 \mathrm{~A}} \mathrm{R}$ transcripts. ${ }^{230,231}$ Each $\mathrm{A}_{2 \mathrm{~A}} \mathrm{R}$ transcript contains the same coding region plus an identical 3 'untranslated region (UTR) and a distinct $5^{\prime}$ UTR. This particular feature is conserved among species and might lead to the production of various transcripts with different $5^{\prime}$ UTRs that control the transport, the translation efficiency, and the selection of the translational start site of the targeted transcript. ${ }^{232,233}$ Accordingly, lipopolysaccharide (LPS) stimulation of human polymorphonuclear neutrophils (PMNs) shifts $\mathrm{A}_{2 \mathrm{~A}} \mathrm{R}$ transcription from a longer $5^{\prime} \mathrm{UTR}$ to a shorter one, possibly increasing translation efficiency. ${ }^{231}$ Therefore, different strategies in the transcriptional control of $\mathrm{A}_{2 \mathrm{~A}} \mathrm{R}$ may underlie differences in expression and signaling in physiological versus pathological conditions.

ADORA2A is a dual coding gene: in addition to the $\mathrm{A}_{2 \mathrm{~A}} \mathrm{R}$ protein, a 134-amino acid protein (uORF5) can be translated from an upstream open reading frame of the rat $\mathrm{A}_{2 \mathrm{~A}} \mathrm{R}$ gene. ${ }^{234-236}$ Expression of uORF5 was detected in rat striatum, associated with high $\mathrm{A}_{2 \mathrm{~A}} \mathrm{R}$ mRNA levels. ${ }^{237}$ In a rat pheochromocytoma line (PC12), uORF5 suppresses the activity of the transcription activator protein 1 (AP1) and regulates expression of proteins implicated in MAPK pathway. ${ }^{237}$ Interestingly, $\mathrm{A}_{2 \mathrm{~A}} \mathrm{R}$ activation led to a PKA-dependent increase in uORF5 protein levels at the posttranscriptional level, suggesting that uORF5 might act downstream of $\mathrm{A}_{2 \mathrm{~A}} \mathrm{R}$ and regulate $\mathrm{A}_{2 \mathrm{~A}} \mathrm{R}$ activity. ${ }^{237}$

Epigenetic $A_{2 A} R$ regulation. Several agents have been implicated in the epigenetic regulation of ADORA2A, including transcription factors (CREB, NF-1, NF $\kappa \mathrm{B}$, 
PPARgamma, YY-1, and ZBP-89), proinflammatory cytokines (IL-1 $\beta$ and TNF-alpha), microRNA (miRNAs; miRNA-214, miRNA-34b, miRNA-15, and miRNA16), and DNA methylation. ${ }^{238-251}$

In polymorphonuclear leukocytes, the increase in $\mathrm{A}_{2 \mathrm{~A}} \mathrm{R}$ mRNA expression upon LPS stimulation correlates inversely with the expression levels of miRNA-214, miRNA-15, and miRNA-16. ${ }^{247}$ Reduced miRNA-34b levels were related to increased $\mathrm{A}_{2 \mathrm{~A}} \mathrm{R}$ levels in the putamen of PD patients, although alterations in miRNA214, miRNA-15, and miRNA-16 were not found. ${ }^{243}$

Both genetic and pharmacological approaches revealed that DNA methylation by adenosine is receptor-independent. Genetic removal of ADK in the mouse forebrain, which leads to the elevation of intracellular adenosine, causes the reduction of DNA methylation. Chronic administration of an ADK inhibitor (5-iodotubercidin) in mice decreased global DNA methylation in the hippocampus of WT or $A_{1} R$ KO mice. ${ }^{252}$ Besides, liver-rescued adenosine deaminase (ADA) KO mice show elevated adenosine level and DNA hypomethylation in the placenta. A similar phenomenon is observed in liver-rescued ADA and $A D O R A 2 B$ double KO mice. ${ }^{253}$ Furthermore, an in vitro study showed that $\mathrm{A}_{2 \mathrm{~A}} \mathrm{R}$ (ZM 241385) and $\mathrm{A}_{2 \mathrm{~B}} \mathrm{R}$ (MRS1754) antagonism does not change adenosine-induced hypomethylation in human umbilical vein endothelial cells. ${ }^{254}$

Interestingly, although epigenetic effect of adenosine is receptor-independent, adenosine receptor gene(s) could also be epigenetically modified through global methylation. A previous study has identified three $\mathrm{CpG}$ islands in the $5^{\prime} \mathrm{UTR}$ region of human ADORA2A, which regulates its gene and protein expression. Buira et al. used different types of cell lines, including HeLa (epithelial cells), SH-SY5Y (neuroblastoma cells), and U87-MG (glioblastoma cells), which have distinct $\mathrm{A}_{2 \mathrm{~A}} \mathrm{R}$ mRNA expression levels to demonstrate the impact of DNA methylation on $\mathrm{A}_{2 \mathrm{~A}} \mathrm{R}$ expression. The endogenous $\mathrm{A}_{2 \mathrm{~A}} \mathrm{R}$ mRNA expression levels are inversely correlated with DNA methylation level in these cells. $^{241}$ DNA-methylation inhibitor (5-azacytidine) or activator (S-adenosyl-L-methionine) treatments increase or decrease $A_{2 A} R$ expression, respectively. ${ }^{241}$ Furthermore, the same group observed the same phenomenon in the two cerebral regions (putamen and cerebellum) of the human brain. ${ }^{242}$

Besides DNA methylation, histone acetylation is a mechanism that allows tight but transient regulation of gene expression. Histone H3 acetylation is one of the most frequent epigenetic mechanism that increases the expression of the target genes by chromatin opening. We observed that chronic $\mathrm{A}_{2 \mathrm{~A}} \mathrm{R}$ blockade with KW6002 increased $A D O R A 2 A$ acetylation (unpublished data), consistent with the increase in $\mathrm{A}_{2 \mathrm{~A}} \mathrm{R}$ expression observed upon treatment, ${ }^{100,224}$ providing new insights into KW6002 mechanism of action.
In conclusion, these aspects of gene regulation upon aging are still poorly understood and surely deserve much more attention if one wants to pinpoint the agerelated $\mathrm{A}_{2 \mathrm{~A}} \mathrm{R}$ expression shift which impacts on cognition. Very relevant steps were taken recently, when for the first time, a SNP in the ADORA2A gene was associated with episodic memory performance, hippocampal volume, and total tau in CSF in MCI and AD patients. ${ }^{228}$ This polymorphism occurs in a noncoding region, upstream to the coding sequence and it was just suggested, but not studied, that it could imply alterations in $\mathrm{A}_{2 \mathrm{~A}} \mathrm{R}$ expression.

\section{Caffeine effects in aging and $A D$}

Caffeine is the world's most popular psychoactive drug and is consumed by millions of people. While short-term CNS stimulating effects of caffeine are well-known, ${ }^{255}$ the long-term impact remains not completely clear. The Finland, Italy, and the Netherlands Elderly (FINE) Study showed that coffee intake was inversely associated with cognitive decline. In fact, elderly men $(70 \pm 10$ years) who consumed coffee had a two times smaller 10-year cognitive decline than nonconsumers. ${ }^{256}$ Accordingly, there was also an inverse association between the number of cups of coffee consumed per day and 10-year cognitive decline, with the least decline for men consuming three cups per day. ${ }^{256}$ Furthermore, in the Three City Study, with a sample of subjects aged 65 years and older, consumption of at least three cups of coffee per day was associated with less decline in verbal memory in women. ${ }^{257}$ On the opposite, coffee had no significant protective effect in women with less than two daily units. ${ }^{257}$

Importantly, other studies support a role for caffeine in the prevention of $\mathrm{AD}$. A retrospective study reported an inverse correlation between coffee consumption and disease onset-AD patients had an average daily caffeine intake of $73.9 \pm 97.9 \mathrm{mg}$ during the 20 years before AD diagnosis, whereas the control had an average daily caffeine intake of $198.7 \pm 135.7 \mathrm{mg}$ during the corresponding 20 years of their lifetimes. ${ }^{258}$ In a prospective study, daily coffee drinking decreased the risk of $\mathrm{AD}$ by $31 \%$ during a 5 -year follow-up. ${ }^{259}$ In line with those findings, moderate coffee drinkers (three to five cups of coffee per day) had a $65-70 \%$ decreased risk of dementia and a $62-64 \%$ decreased risk of AD compared with low coffee consumers. ${ }^{260}$ Furthermore, another prospective study showed that plasma caffeine levels at study onset were substantially lower $(-51 \%)$ in MCI subjects who later progressed to dementia compared to levels in stable MCI subjects. Also, plasma caffeine levels $>1200 \mathrm{ng} / \mathrm{mL}$ $(\approx 6 \mu \mathrm{M})$ in MCI subjects were associated with no conversion to dementia during the ensuing 2/4-year followup period. ${ }^{261}$ However, coffee and caffeine intake in midlife were not associated with cognitive impairment, 
dementia, or individual neuropathologic lesions. ${ }^{262}$ It is noteworthy that higher caffeine intake was associated with lower odds of having any neuropathological lesions at autopsy, including AD-related lesions, microvascular ischemic lesions, cortical Lewy bodies, hippocampal sclerosis, or generalized atrophy. ${ }^{262}$

The beneficial effects of caffeine in humans are not confined to AD. Epidemiological studies show an inverse relationship between the consumption of caffeine and the risk of developing $\mathrm{PD}^{263,264}$ and two ADORA2A polymorphisms (r71651683 and rs5996696) were inversely associated with PD risk. ${ }^{265}$ Although the mechanism was not directly addressed, the beneficial effects seem to be achieved via $\mathrm{A}_{2 \mathrm{~A}} \mathrm{R}$ blockade. ${ }^{266,267}$ Caffeine is metabolized primarily by cytochrome P450 1A2 (CYP1A2). An A to C substitution at position 163 in the CYP1A2 decreases enzyme inducibility. However, there is no association between this genetic alteration and caffeine consumption. In the brain, $\mathrm{A}_{2 \mathrm{~A}} \mathrm{R}$ activation has an important role in the stimulating and reinforcing properties of caffeine ${ }^{190,268}$ and $A_{2 A} \mathrm{R} K O$ mice have less appetite for caffeine than WT littermates. ${ }^{269}$ A $\mathrm{C}$ to $\mathrm{T}$ substitution at position 1083 in the $A D O R A 2 A$ gene was associated with caffeine-induced anxiety among nonhabitual caffeine consumers ${ }^{270}$ and the probability of having such mutation decreases as the caffeine intake increases in a population, and people with that genotype are more likely to limit their caffeine intake. ${ }^{271}$

Caffeine consumption has been shown to improve the memory performance in multiple AD mice models, ascertaining its protective properties against cognitive impairment and in favor of improved memory retention (see Kolahdouzan and Hamadeh ${ }^{272}$ ). In aged rodents, perfusion of caffeine rescued neuronal $\mathrm{A}_{2 \mathrm{~A}} \mathrm{R}$-driven synaptic plasticity shift in the hippocampus, ${ }^{100}$ while having no effects in excitatory CA1 currents in young animals. ${ }^{194}$ In aged animals, chronic intake of caffeine for 12 months prevents age-associated recognition memory decline, possibly by restoring BDNF signaling. ${ }^{273}$ Chronic caffeine consumption also rescued synaptic and memory impairments in a mouse model of chronic unpredictable stress in a manner similar to selective $\mathrm{A}_{2 \mathrm{~A}} \mathrm{R}$ antagonist (KW6002) administration or $\mathrm{A}_{2 \mathrm{~A}} \mathrm{R}$ genetic deletion selectively in neurons, ${ }^{274}$ being that stress is a physiopathological condition associated with upsurge of $\mathrm{A}_{2 \mathrm{~A}} \mathrm{R}$ and hippocampal dysfunction. ${ }^{224,274}$ Memory deficits were prevented by caffeine in transgenic mouse models of Alzheimer's disease, both amyloid and Tau-based. ${ }^{195,275-277}$

The caffeine-mediated beneficial effects also included decrease in several proinflammatory (CD68, CD45, TLR2, CCL4, and TNF $\alpha$ ) and oxidative stress (Nrf2, MnSOD, and EAAT3) markers found upregulated in the hippocampus of THY-Tau22 animals. ${ }^{278}$ Interestingly, caffeine reduces tau phosphorylation in different residues from the ones observed with $\mathrm{A}_{2 \mathrm{~A}} \mathrm{R}$ antagonist genetic deletion $^{195,278}$ and decreases the amount of Tau proteolytic fragments, ${ }^{278}$ a pathological feature that is not influenced by genetic deletion. ${ }^{195}$ These results suggest that regulation of Tau by caffeine may result from a wider range of actions than from inhibition of $\mathrm{A}_{2 \mathrm{~A}} \mathrm{R}$ function alone.

\section{Conclusion}

In summary, age-related memory impairments are explained by changes in neuronal and synaptic morphology and function, namely reduction in the amplitude of the Schaffer collaterals-induced fEPSP and in PSD area in CA1. ${ }^{62-64}$ These results, associated with maintenance of the unitary EPSP size, ${ }^{66}$ suggest that aging might not be associated with alterations in the strength of individual synaptic connections, but instead with an increase in nonfunctional or silent synapses in the hippocampus.

The changes observed at individual synapses directly affect synaptic plasticity mechanisms, namely an alteration in the susceptibility to induce LTP and LTD due to a shift in $\mathrm{Ca}^{2+}$-dependent induction mechanisms. ${ }^{84,99}$ Together with impairments in calcium buffering and influx mechanisms, such as via NMDAR and L-type VDCC (voltage-dependent calcium channels), ${ }^{103,111,112,121-125}$ these observations support the calcium hypothesis of aging, which implicates raised intracellular $\mathrm{Ca}^{2+}$ as the major source of functional impairment and degeneration in aged neurons. ${ }^{104-106}$

Caffeine is the world's most popular psychoactive drug and is consumed by millions of people. Multiple prospective and retrospective studies emphasize the role of caffeine, adenosine receptor antagonist, in slowing down cognitive decline in aged population and reducing the risk of developing AD. Although the mechanism is not yet disclosed, the beneficial effects seem to be achieved via $\mathrm{A}_{2 \mathrm{~A}} \mathrm{R}$ blockade. ${ }^{266,267}$

$\mathrm{A}_{2 \mathrm{~A}} \mathrm{R}$ expression and signaling is profoundly altered in the hippocampus upon aging. $\mathrm{A}_{2 \mathrm{~A}} \mathrm{R}$ density and coupling to $G$ protein is increased, ${ }^{100,144,197-199}$ probably enhancing the efficiency of this receptor to facilitate neurotransmitters release in glutamatergic synapses by a presynaptic mechanism. ${ }^{197}$ Interestingly, neuronal $\mathrm{A}_{2 \mathrm{~A}} \mathrm{R}$ overexpression in the same magnitude to the one observed in human aging is sufficient to trigger synaptic and cognitive deficits, due to a mGluR5-dependent NMDAR overactivation and linked to enhanced $\mathrm{Ca}^{2+}$ influx, ${ }^{100}$ which recapitulates the main synaptic alterations observed upon aging. Importantly, either $\mathrm{A}_{2 \mathrm{~A}} \mathrm{R}$ pharmacological blockade or genetic deletion prevents synaptic and memory impairments in aged rodents and several AD models. ${ }^{100,222,223,278}$

Because of the diversity and complexity of the adenosine receptor-dependent and independent regulatory mechanisms, a better understanding of the precise mechanism of adenosine and its receptors in pathophysiological conditions in different brain regions and CNS cell types will allow the development of novel therapeutic strategies for synaptic and memory dysfunction upon aging and AD. 


\section{Acknowledgment}

We acknowledge Ching-Pang Chang for the important contribution for the section on the regulation of $A D O R A 2 A$ gene expression.

\section{Authors' Contributions}

M.T.-F. has written the article. M.T.-F., J.E.C., P.A.P., and L.V.L. discussed the article. All authors have reviewed and approved the article.

\section{Author Disclosure Statement}

No competing financial interests exist.

\section{Funding Information}

M.T.-F. and J.E.C. were supported by a fellowship from Fundação para a Ciência e Tecnologia (FCT, Portugal); L.V.L is an Investigator CEEC-FCT. P.A.P. is supported by EU Joint Program-Neurodegenerative Disease Research (JPND) project CIRCPROT (jointly funded by BMBF, MIUR, and EU Horizon 2020 grant agreement no. 643417). This study was also funded by Santa Casa da Misericórdia - Mantero Belard 2018 (MB-7-2018) and by UID/BIM/50005/2019, project funded by Fundação para a Ciência e a Tecnologia (FCT)/ Ministério da Ciência, Tecnologia e Ensino Superior (MCTES) through Fundos do Orçamento de Estado.

\section{References}

1. Morrison JH, Hof PR. Life and death of neurons in the aging brain. Science. 1997;278:412-419.

2. Bartsch T, Wulff P. The hippocampus in aging and disease: From plasticity to vulnerability. Neuroscience. 2015;309:1-16.

3. Strange BA, Witter MP, Lein ES, et al. Functional organization of the hippocampal longitudinal axis. Nat Rev Neurosci. 2014;15:655-669.

4. Amaral DG, Scharfman HE, Lavenex P. The dentate gyrus: Fundamental neuroanatomical organization (dentate gyrus for dummies). Prog Brain Res. 2007;163:3-22.

5. Lisman JE. Relating hippocampal circuitry to function: Recall of memory sequences by reciprocal dentate-CA3 interactions. Neuron. 1999;22:233-242.

6. Lisman JE, Otmakhova NA. Storage, recall, and novelty detection of sequences by the hippocampus: Elaborating on the SOCRATIC model to account for normal and aberrant effects of dopamine. Hippocampus. 2001;11:551-568.

7. Lavenex P, Amaral DG. Hippocampal-neocortical interaction: A hierarchy of associativity. Hippocampus. 2000;10:420-430.

8. Megías M, Emri Z, Freund TF, et al. Total number and distribution of inhibitory and excitatory synapses on hippocampal CA1 pyramidal cells. Neuroscience. 2001; 102:527-540.

9. Andersen P, ed. The Hippocampus Book. Oxford; New York: Oxford University Press; 2007.

10. Wheeler DW, White CM, Rees CL, et al. Hippocampome.org: A knowledge base of neuron types in the rodent hippocampus. ELife. 4. DOI: 10.7554/eLife.09960.
11. Bezaire MJ, Soltesz I. Quantitative assessment of CA1 local circuits: Knowledge base for interneuronpyramidal cell connectivity: Quantitative assessment of ca1 local circuits. Hippocampus. 2013;23:751-785.

12. Gasbarri A, Sulli A, Packard MG. The dopaminergic mesencephalic projections to the hippocampal formation in the rat. Prog Neuropsychopharmacol Biol Psychiatry. 1997;21:1-22.

13. McNamara CG, Dupret D. Two sources of dopamine for the hippocampus. Trends Neurosci. 2017; 40:383-384.

14. Fisahn A, Pike FG, Buhl EH, et al. Cholinergic induction of network oscillations at $40 \mathrm{~Hz}$ in the hippocampus in vitro. Nature. 1998;394:186-189.

15. Moore RY, Halaris AE. Hippocampal innervation by serotonin neurons of the midbrain raphe in the rat. J Comp Neurol. 1975;164:171-183.

16. Ohmura Y, Izumi T, Yamaguchi T, et al. The serotonergic projection from the median raphe nucleus to the ventral hippocampus is involved in the retrieval of fear memory through the corticotropin-releasing factor type 2 receptor. Neuropsychopharmacology. 2010;35: 1271-1278.

17. Shepherd GM, Harris KM. Three-dimensional structure and composition of $\mathrm{CA} 3 \longrightarrow \mathrm{CA} 1$ axons in rat hippocampal slices: Implications for presynaptic connectivity and compartmentalization. J Neurosci. 1998;18: 8300-8310.

18. Hassel B, Dingledine R. Glutamate and glutamate receptors. In: Basic Neurochemistry. G.J. Siegel, B.W. Agranoff, R.W. Albers, S.K. Fisher and M.D. Uhler (Eds). Philadelphia: Elsevier; 2012: pp. 342-366.

19. Kennedy MB. The postsynaptic density at glutamatergic synapses. Trends Neurosci. 1997;20:264-268.

20. Uchigashima M, Ohtsuka T, Kobayashi K, et al. Dopamine synapse is a neuroligin-2-mediated contact between dopaminergic presynaptic and GABAergic postsynaptic structures. Proc Natl Acad Sci U S A. 2016;113:4206-4211.

21. Citri A, Malenka RC. Synaptic plasticity: Multiple forms, functions, and mechanisms. Neuropsychopharmacology. 2008;33:18-41.

22. Abraham WC, Christie BR, Logan B, et al. Immediate early gene expression associated with the persistence of heterosynaptic long-term depression in the hippocampus. Proc Natl Acad Sci U S A. 1994;91: 10049-10053.

23. Abraham WC, Logan B, Greenwood JM, et al. Induction and experience-dependent consolidation of stable long-term potentiation lasting months in the hippocampus. J Neurosci. 2002;22:9626-9634.

24. Staubli U, Scafidi J. Studies on long-term depression in area CA1 of the anesthetized and freely moving rat. J Neurosci. 1997; 17:4820-4828.

25. Lynch MA. Long-term potentiation and memory. Physiol Rev. 2004;84:87-136.

26. Ziemann U, Ilić TV, Iliać TV, et al. Learning modifies subsequent induction of long-term potentiation-like and long-term depression-like plasticity in human motor cortex. J Neurosci. 2004;24:1666-1672.

27. Dong Z, Bai Y, Wu X, et al. Hippocampal long-term depression mediates spatial reversal learning in the Morris water maze. Neuropharmacology. 2013;64:65-73. 
28. Ge Y, Dong Z, Bagot RC, et al. Hippocampal long-term depression is required for the consolidation of spatial memory. Proc Natl Acad Sci U S A. 2010;107: 16697-16702.

29. Stevens CF. A million dollar question: Does LTP $=$ memory? Neuron. 1998;20:1-2.

30. Squire LR, Kandel ER. Memory: From Mind to Molecules. 2nd ed. Greenwood Village, CO: Roberts; 2009.

31. Huganir RL, Nicoll RA. AMPARs and synaptic plasticity: The last 25 years. Neuron. 2013;80:704-717.

32. Silva AJ, Stevens CF, Tonegawa S, et al. Deficient hippocampal long-term potentiation in alpha-calciumcalmodulin kinase II mutant mice. Science. 1992;257: 201-206.

33. Mulkey RM, Endo S, Shenolikar S, et al. Involvement of a calcineurin/inhibitor-1 phosphatase cascade in hippocampal long-term depression. Nature. 1994;369: 486-488.

34. Barria A, Muller D, Derkach V, et al. Regulatory phosphorylation of AMPA-type glutamate receptors by CaM-KII during long-term potentiation. Science. 1997;276:2042-2045.

35. Kameyama K, Lee HK, Bear MF, et al. Involvement of a postsynaptic protein kinase A substrate in the expression of homosynaptic long-term depression. Neuron. 1998;21:1163-1175.

36. Lee HK, Kameyama K, Huganir RL et al. NMDA induces long-term synaptic depression and dephosphorylation of the GluR1 subunit of AMPA receptors in hippocampus. Neuron. 1998;21:1151-1162.

37. Lee HK, Barbarosie M, Kameyama K et al. Regulation of distinct AMPA receptor phosphorylation sites during bidirectional synaptic plasticity. Nature. 2000;405: 955-959.

38. Turrigiano G. Homeostatic synaptic plasticity: Local and global mechanisms for stabilizing neuronal function. Cold Spring Harb Perspect Biol. 2012;4:1-17. DOI: 10.1101/cshperspect.a005736.

39. von der Malsburg C. Self-organization of orientation sensitive cells in the striate cortex. Kybernetik. 1973; 14:85-100.

40. Miller KD, MacKay DJC. The role of constraints in Hebbian learning. Neural Comput. 1994;6:100-126.

41. Hobbiss AF, Ramiro-Cortés Y, Israely I. Homeostatic plasticity scales dendritic spine volumes and changes the threshold and specificity of Hebbian plasticity. iScience. 2018;8:161-174.

42. Reitz C, Brayne C, Mayeux R. Epidemiology of Alzheimer disease. Nat Rev Neurol. 2011;7:137-152.

43. Barnes CA. Memory deficits associated with senescence: A neurophysiological and behavioral study in the rat. J Comp Physiol Psychol. 1979;93:74-104.

44. Colombo PJ, Wetsel WC, Gallagher M. Spatial memory is related to hippocampal subcellular concentrations of calcium-dependent protein kinase $\mathrm{C}$ isoforms in young and aged rats. Proc Natl Acad Sci U S A. 1997;94:14195-14199.

45. Erickson CA, Barnes CA. The neurobiology of memory changes in normal aging. Exp Gerontol. 2003;38: 61-69.

46. Mabry TR, McCarty R, Gold PE, et al. Age and stress history effects on spatial performance in a swim task in Fischer-344 rats. Neurobiol Learn Mem. 1996;66:1-10.
47. Oler JA, Markus EJ. Age-related deficits on the radial maze and in fear conditioning: Hippocampal processing and consolidation. Hippocampus. 1998;8:402-415.

48. Tanila H, Shapiro M, Gallagher M, et al. Brain aging: Changes in the nature of information coding by the hippocampus. J Neurosci. 1997;17:5155-5166.

49. Burke SN, Barnes CA. Neural plasticity in the ageing brain. Nat Rev Neurosci. 2006;7:30-40.

50. Ball MJ. Neuronal loss, neurofibrillary tangles and granulovacuolar degeneration in the hippocampus with ageing and dementia. A quantitative study. Acta Neuropathol (Berl). 1977;37:111-118.

51. Brizzee KR, Ordy JM, Bartus RT. Localization of cellular changes within multimodal sensory regions in aged monkey brain: Possible implications for agerelated cognitive loss. Neurobiol Aging. 1980;1:45-52.

52. Brody H. Organization of the cerebral cortex. III. A study of aging in the human cerebral cortex. J Comp Neurol. 1955;102:511-516.

53. Coleman PD, Flood DG. Neuron numbers and dendritic extent in normal aging and Alzheimer's disease. Neurobiol Aging. 1987;8:521-545.

54. Gazzaley AH, Thakker MM, Hof PR, et al. Preserved number of entorhinal cortex layer II neurons in aged macaque monkeys. Neurobiol Aging. 1997;18:549-553.

55. Keuker JIH, Luiten PGM, Fuchs E. Preservation of hippocampal neuron numbers in aged rhesus monkeys. Neurobiol Aging. 2003;24:157-165.

56. Merrill DA, Roberts JA, Tuszynski MH. Conservation of neuron number and size in entorhinal cortex layers II, III, and V/VI of aged primates. J Comp Neurol. 2000;422:396-401.

57. Pakkenberg B, Gundersen HJ. Neocortical neuron number in humans: Effect of sex and age. J Comp Neurol. 1997;384:312-320.

58. Peters A, Leahu D, Moss MB, et al. The effects of aging on area 46 of the frontal cortex of the rhesus monkey. Cereb Cortex. 1994;4:621-635.

59. West MJ. New stereological methods for counting neurons. Neurobiol Aging. 1993;14:275-285.

60. Scheff SW, Price DA, Schmitt FA, et al. Hippocampal synaptic loss in early Alzheimer's disease and mild cognitive impairment. Neurobiol Aging. 2006;27:1372-1384.

61. Bear MF, Cooper LN, Ebner FF. A physiological basis for a theory of synapse modification. Science. 1987; 237:42-48.

62. Barnes CA, Rao G, Foster TC, et al. Region-specific age effects on AMPA sensitivity: Electrophysiological evidence for loss of synaptic contacts in hippocampal field CA1. Hippocampus. 1992;2:457-468.

63. Landfield PW, Pitler TA, Applegate MD. The effects of high $\mathrm{Mg}^{2+}$-to- $\mathrm{Ca}^{2+}$ ratios on frequency potentiation in hippocampal slices of young and aged rats. J Neurophysiol. 1986;56:797-811.

64. Rosenzweig ES, Rao G, McNaughton BL, et al. Role of temporal summation in age-related long-term potentiationinduction deficits. Hippocampus. 1997;7:549-558.

65. Nicholson DA, Yoshida R, Berry RW, et al. Reduction in size of perforated postsynaptic densities in hippocampal axospinous synapses and age-related spatial learning impairments. J Neurosci. 2004;24:7648-7653.

66. Barnes CA, Rao G, Shen J. Age-related decrease in the Nmethyl-D-aspartateR-mediated excitatory postsynaptic 
potential in hippocampal region CA1. Neurobiol Aging. 1997;18:445-452.

67. Burke SN, Barnes CA. Senescent synapses and hippocampal circuit dynamics. Trends Neurosci. 2010;33: 153-161.

68. McEwen BS. Possible mechanisms for atrophy of the human hippocampus. Mol Psychiatry. 1997;2:255-262.

69. Banay-Schwartz M, Lajtha A, Palkovits M. Changes with aging in the levels of amino acids in rat CNS structural elements. I. Glutamate and related amino acids. Neurochem Res. 1989; 14:555-562.

70. Strolin Benedetti M, Cini M, Fusi R, et al. The effects of aging on MAO activity and amino acid levels in rat brain. J Neural Transm Suppl. 1990;29:259-268.

71. Saransaari P, Oja SS. Age-related changes in the uptake and release of glutamate and aspartate in the mouse brain. Mech Ageing Dev. 1995;81:61-71.

72. Freeman GB, Gibson GE. Selective alteration of mouse brain neurotransmitter release with age. Neurobiol Aging. 1987;8:147-152.

73. Najlerahim A, Francis PT, Bowen DM. Age-related alteration in excitatory amino acid neurotransmission in rat brain. Neurobiol Aging. 1990;11:155-158.

74. Gilad GM, Gilad VH, Tizabi Y. Aging and stressinduced changes in choline and glutamate uptake in hippocampus and septum of two rat strains differing in longevity and reactivity to stressors. Int J Dev Neurosci. 1990;8:709-713.

75. Palmer AM, Robichaud PJ, Reiter CT. The release and uptake of excitatory amino acids in rat brain: Effect of aging and oxidative stress. Neurobiol Aging. 1994;15: 103-111.

76. Timmerman $\mathrm{W}$, Westerink BH. Brain microdialysis of GABA and glutamate: What does it signify? Synapse. 1997;27:242-261.

77. Disterhoft JF, Thompson LT, Moyer JR, et al. Calciumdependent afterhyperpolarization and learning in young and aging hippocampus. Life Sci. 1996;59:413-420.

78. Wu WW, Oh MM, Disterhoft JF. Age-related biophysical alterations of hippocampal pyramidal neurons: Implications for learning and memory. Ageing Res Rev. 2002;1:181-207.

79. Tombaugh GC, Rowe WB, Chow AR, et al. Thetafrequency synaptic potentiation in CA1 in vitro distinguishes cognitively impaired from unimpaired aged Fischer 344 rats. J Neurosci. 2002;22:9932-9940.

80. Deupree DL, Bradley J, Turner DA. Age-related alterations in potentiation in the CA1 region in F344 rats. Neurobiol Aging. 1993;14:249-258.

81. Rex CS, Kramár EA, Colgin LL, et al. Long-term potentiation is impaired in middle-aged rats: Regional specificity and reversal by adenosine receptor antagonists. J Neurosci. 2005;25:5956-5966.

82. Sankar R, Shin D, Mazarati AM, et al. Epileptogenesis after status epilepticus reflects age- and modeldependent plasticity. Ann Neurol. 2000;48:580-589.

83. Costenla AR, de Mendonça A, Ribeiro JA. Adenosine modulates synaptic plasticity in hippocampal slices from aged rats. Brain Res. 1999;851:228-234.

84. Kumar A, Thinschmidt JS, Foster TC, et al. Aging effects on the limits and stability of long-term synaptic potentiation and depression in rat hippocampal area CA1. J Neurophysiol. 2007;98:594-601.
85. Landfield PW, Lynch G. Impaired monosynaptic potentiation in in vitro hippocampal slices from aged, memory-deficient rats. J Gerontol. 1977;32:523-533.

86. Landfield PW, McGaugh JL, Lynch G. Impaired synaptic potentiation processes in the hippocampus of aged, memory-deficient rats. Brain Res. 1978;150:85-101.

87. Norris CM, Korol DL, Foster TC. Increased susceptibility to induction of long-term depression and long-term potentiation reversal during aging. J Neurosci. 1996;16: 5382-5392.

88. Diógenes MJ, Costenla AR, Lopes LV, et al. Enhancement of LTP in aged rats is dependent on endogenous BDNF. Neuropsychopharmacology. 2011;36:18231836.

89. Huang Y-Y, Kandel ER. Age-related enhancement of a protein synthesis-dependent late phase of LTP induced by low frequency paired-pulse stimulation in hippocampus. Learn Mem. 2006;13:298-306.

90. Kumar A, Foster TC. Enhanced long-term potentiation during aging is masked by processes involving intracellular calcium stores. J Neurophysiol. 2004;91:2437-2444.

91. Pinho J, Vale R, Batalha VL, et al. Enhanced LTP in aged rats: Detrimental or compensatory? Neuropharmacology. 2017;114:12-19.

92. Bloss EB, Hunter RG, Waters EM, et al. Behavioral and biological effects of chronic S18986, a positive AMPA receptor modulator, during aging. Exp Neurol. 2008; 210:109-117.

93. Radin DP, Zhong S, Purcell R, et al. Acute ampakine treatment ameliorates age-related deficits in long-term potentiation. Biomed Pharmacother. 2016;84:806-809.

94. Jurado S. AMPA receptor trafficking in natural and pathological aging. Front Mol Neurosci. 2017;10:446.

95. Dash PK, Hochner B, Kandel ER. Injection of the cAMP-responsive element into the nucleus of Aplysia sensory neurons blocks long-term facilitation. Nature. 1990;345:718-721.

96. Guzowski JF, McGaugh JL. Antisense oligodeoxynucleotide-mediated disruption of hippocampal cAMP response element binding protein levels impairs consolidation of memory for water maze training. Proc Natl Acad Sci U S A. 1997;94: 2693-2698.

97. Bach ME, Barad M, Son H, et al. Age-related defects in spatial memory are correlated with defects in the late phase of hippocampal long-term potentiation in vitro and are attenuated by drugs that enhance the cAMP signaling pathway. Proc Natl Acad Sci U S A. 1999;96: 5280-5285.

98. Porte Y, Buhot M-C, Mons N. Alteration of CREB phosphorylation and spatial memory deficits in aged 129T2/Sv mice. Neurobiol Aging. 2008;29:1533-1546.

99. Foster TC, Kumar A. Susceptibility to induction of long-term depression is associated with impaired memory in aged Fischer 344 rats. Neurobiol Learn Mem. 2007;87:522-535.

100. Temido-Ferreira M, Ferreira DG, Batalha VL, et al. Age-related shift in LTD is dependent on neuronal adenosine A2Areceptors interplay with mGluR5 and NMDA receptors. Mol Psychiatry. 2018. DOI: 10.1038/s41380-018-0110-9.

101. Foster TC, Kumar A. Calcium dysregulation in the aging brain. Neuroscientist. 2002;8:297-301. 
102. Foster TC, Norris CM. Age-associated changes in $\mathrm{Ca}(2+)$-dependent processes: Relation to hippocampal synaptic plasticity. Hippocampus. 1997;7:602-612.

103. Thibault O, Landfield PW. Increase in single L-type calcium channels in hippocampal neurons during aging. Science. 1996;272:1017-1020.

104. Khachaturian ZS. The role of calcium regulation in brain aging: Reexamination of a hypothesis. Aging (Milano). 1989;1:17-34.

105. Khachaturian ZS. Calcium hypothesis of Alzheimer's disease and brain aging. Ann N Y Acad Sci. 1994; 747:1-11.

106. Verkhratsky A, Toescu EC. Calcium and neuronal ageing. Trends Neurosci. 1998;21:2-7.

107. Arundine M, Tymianski M. Molecular mechanisms of calcium-dependent neurodegeneration in excitotoxicity. Cell Calcium. 2003;34:325-337.

108. Delorenzo RJ, Sun DA, Deshpande LS. Cellular mechanisms underlying acquired epilepsy: The calcium hypothesis of the induction and maintainance of epilepsy. Pharmacol Ther. 2005;105:229-266.

109. Hajieva P, Kuhlmann C, Luhmann HJ, et al. Impaired calcium homeostasis in aged hippocampal neurons. Neurosci Lett. 2009;451:119-123.

110. Raza M, Deshpande LS, Blair RE, et al. Aging is associated with elevated intracellular calcium levels and altered calcium homeostatic mechanisms in hippocampal neurons. Neurosci Lett. 2007;418:77-81.

111. Núñez-Santana FL, Oh MM, Antion MD, et al. Surface L-type $\mathrm{Ca}^{2+}$ channel expression levels are increased in aged hippocampus. Aging Cell. 2014;13:111-120.

112. Veng LM, Browning MD. Regionally selective alterations in expression of the alpha(1D) subunit $(\mathrm{Ca}(\mathrm{v}) 1.3)$ of L-type calcium channels in the hippocampus of aged rats. Brain Res Mol Brain Res. 2002;107:120-127.

113. de Jong GI, Naber PA, Van der Zee EA, et al. Agerelated loss of calcium binding proteins in rabbit hippocampus. Neurobiol Aging. 1996;17:459-465.

114. Satrústegui J, Villalba M, Pereira R, et al. Cytosolic and mitochondrial calcium in synaptosomes during aging. Life Sci. 1996;59:429-434.

115. Villa A, Meldolesi J. The control of $\mathrm{Ca}^{2+}$ homeostasis: Role of intracellular rapidly exchanging $\mathrm{Ca}^{2+}$ stores. Cell Biol Int. 1994;18:301-307.

116. Martinez-Serrano A, Blanco P, Satrústegui J. Calcium binding to the cytosol and calcium extrusion mechanisms in intact synaptosomes and their alterations with aging. J Biol Chem. 1992;267:4672-4679.

117. Michaelis ML, Johe K, Kitos TE. Age-dependent alterations in synaptic membrane systems for $\mathrm{Ca}^{2+}$ regulation. Mech Ageing Dev. 1984;25:215-225.

118. Michaelis ML, Foster CT, Jayawickreme C. Regulation of calcium levels in brain tissue from adult and aged rats. Mech Ageing Dev. 1992;62:291-306.

119. Gibson G, Perrino P, Dienel GA. In vivo brain calcium homeostasis during aging. Mech Ageing Dev. 1986;37: $1-12$.

120. Tsien JZ, Huerta PT, Tonegawa S. The essential role of hippocampal CA1 NMDA receptor-dependent synaptic plasticity in spatial memory. Cell. 1996;87:1327-1338.

121. Jouvenceau A, Dutar P, Billard JM. Alteration of NMDA receptor-mediated synaptic responses in CA1 area of the aged rat hippocampus: Contribution of
GABAergic and cholinergic deficits. Hippocampus. 1998;8:627-637.

122. Serra M, Ghiani CA, Foddi MC, et al. NMDA receptor function is enhanced in the hippocampus of aged rats. Neurochem Res. 1994;19:483-487.

123. Ingram DK, Garofalo P, Spangler EL, et al. Reduced density of NMDA receptors and increased sensitivity to dizocilpine-induced learning impairment in aged rats. Brain Res. 1992;580:273-280.

124. Topic B, Willuhn I, Palomero-Gallagher $\mathrm{N}$, et al. Impaired maze performance in aged rats is accompanied by increased density of NMDA, 5-HT1A, and alpha-adrenoceptor binding in hippocampus. Hippocampus. 2007;17:68-77.

125. Kumar A. NMDA receptor function during senescence: implication on cognitive performance. Front Neurosci. 2015;9:473.

126. Franceschi $C$, Garagnani $P$, Parini $P$, et al. Inflammaging: A new immune-metabolic viewpoint for age-related diseases. Nat Rev Endocrinol. 2018;14:576-590.

127. Pelvig DP, Pakkenberg H, Stark AK, et al. Neocortical glial cell numbers in human brains. Neurobiol Aging. 2008;29:1754-1762.

128. Fabricius K, Jacobsen JS, Pakkenberg B. Effect of age on neocortical brain cells in 90+ year old human femalesA cell counting study. Neurobiol Aging. 2013;34:91-99.

129. Grosche A, Grosche J, Tackenberg M, et al. Versatile and simple approach to determine astrocyte territories in mouse neocortex and hippocampus. PLoS One. 2013;8:e69143.

130. Lalo U, Palygin O, North RA, et al. Age-dependent remodelling of ionotropic signalling in cortical astroglia. Aging Cell. 2011;10:392-402.

131. Palygin O, Lalo U, Verkhratsky A, et al. Ionotropic NMDA and P2X1/5 receptors mediate synaptically induced $\mathrm{Ca}^{2+}$ signalling in cortical astrocytes. Cell Calcium. 2010;48:225-231.

132. Kress BT, Iliff JJ, Xia M, et al. Impairment of paravascular clearance pathways in the aging brain. Ann Neurol. 2014;76:845-861.

133. Perry VH, Matyszak MK, Fearn S. Altered antigen expression of microglia in the aged rodent CNS. Glia. 1993;7:60-67.

134. Ogura K, Ogawa M, Yoshida M. Effects of ageing on microglia in the normal rat brain: Immunohistochemical observations. Neuroreport. 1994;5:1224-1226.

135. Sheffield LG, Berman NE. Microglial expression of MHC class II increases in normal aging of nonhuman primates. Neurobiol Aging. 1998;19:47-55.

136. Henry CJ, Huang Y, Wynne AM, et al. Peripheral lipopolysaccharide (LPS) challenge promotes microglial hyperactivity in aged mice that is associated with exaggerated induction of both pro-inflammatory IL-1beta and anti-inflammatory IL-10 cytokines. Brain Behav Immun. 2009;23:309-317.

137. VanGuilder HD, Bixler GV, Brucklacher RM, et al. Concurrent hippocampal induction of MHC II pathway components and glial activation with advanced aging is not correlated with cognitive impairment. J Neuroinflammation. 2011;8:138.

138. Wong AM, Patel NV, Patel NK, et al. Macrosialin increases during normal brain aging are attenuated by caloric restriction. Neurosci Lett. 2005;390:76-80. 
139. Griffin R, Nally R, Nolan Y, et al. The age-related attenuation in long-term potentiation is associated with microglial activation. J Neurochem. 2006;99:1263-1272.

140. Letiembre M, Hao W, Liu Y, et al. Innate immune receptor expression in normal brain aging. Neuroscience. 2007; 146:248-254.

141. Streit WJ, Sammons NW, Kuhns AJ, et al. Dystrophic microglia in the aging human brain. Glia. 2004;45: 208-212.

142. Davies DS, Ma J, Jegathees T, et al. Microglia show altered morphology and reduced arborization in human brain during aging and Alzheimer's disease. Brain Pathol. 2017;27:795-808.

143. Lopes LV, Cunha RA, Kull B, et al. Adenosine A(2A) receptor facilitation of hippocampal synaptic transmission is dependent on tonic $\mathrm{A}(1)$ receptor inhibition. Neuroscience. 2002;112:319-329.

144. Rebola N, Sebastião AM, de Mendonca A, et al. Enhanced adenosine $\mathrm{A}_{2 \mathrm{~A}}$ receptor facilitation of synaptic transmission in the hippocampus of aged rats. J Neurophysiol. 2003;90:1295-1303.

145. Tebano MT, Martire A, Potenza RL, et al. Adenosine $\mathrm{A}(2 \mathrm{~A})$ receptors are required for normal BDNF levels and BDNF-induced potentiation of synaptic transmission in the mouse hippocampus. J Neurochem. 2008; 104:279-286.

146. Shindou T, Nonaka H, Richardson PJ, et al. Presynaptic adenosine $\mathrm{A}_{2 \mathrm{~A}}$ receptors enhance GABAergic synaptic transmission via a cyclic AMP dependent mechanism in the rat globus pallidus. Br J Pharmacol. 2002;136:296302.

147. Cristóvão-Ferreira S, Navarro G, Brugarolas M, et al. A1R-A2AR heteromers coupled to Gs and G i/0 proteins modulate GABA transport into astrocytes. Purinergic Signal. 2013;9:433-449.

148. Linden J. Molecular approach to adenosine receptors: Receptor-mediated mechanisms of tissue protection. Annu Rev Pharmacol Toxicol. 2001;41:775-787.

149. Reppert SM, Weaver DR, Stehle JH, et al. Molecular cloning and characterization of a rat A1-adenosine receptor that is widely expressed in brain and spinal cord. Mol Endocrinol. 1991;5:1037-1048.

150. Jarvis MF, Williams M. Direct autoradiographic localization of adenosine $\mathrm{A} 2$ receptors in the rat brain using the A2-selective agonist, [3H]CGS 21680. Eur J Pharmacol. 1989;168:243-246.

151. Cunha RA, Johansson B, van der Ploeg I, et al. Evidence for functionally important adenosine $\mathrm{A}_{2 \mathrm{a}}$ receptors in the rat hippocampus. Brain Res. 1994;649: 208-216.

152. Kirk IP, Richardson PJ. Further characterization of $[3 \mathrm{H}]-\mathrm{CGS} 21680$ binding sites in the rat striatum and cortex. Br J Pharmacol. 1995;114:537-543.

153. Rebola N, Canas PM, Oliveira CR, et al. Different synaptic and subsynaptic localization of adenosine $\mathrm{A}_{2 \mathrm{~A}}$ receptors in the hippocampus and striatum of the rat. Neuroscience. 2005;132:893-903.

154. Cunha RA, Ribeiro JA. Purinergic modulation of [(3)H]GABA release from rat hippocampal nerve terminals. Neuropharmacology. 2000;39:1156-1167.

155. Rombo DM, Newton K, Nissen W, et al. Synaptic mechanisms of adenosine $\mathrm{A}_{2 \mathrm{~A}}$ receptor-mediated hy- perexcitability in the hippocampus. Hippocampus. 2015;25:566-580.

156. Borycz J, Pereira MF, Melani A, et al. Differential glutamate-dependent and glutamate-independent adenosine A1 receptor-mediated modulation of dopamine release in different striatal compartments. J Neurochem. 2007;101:355-363.

157. Garção P, Szabó EC, Wopereis S, et al. Functional interaction between pre-synaptic $\alpha 6 \beta 2$-containing nicotinic and adenosine $A_{2 A}$ receptors in the control of dopamine release in the rat striatum. Br J Pharmacol. 2013;169:1600-1611.

158. Cunha RA, Johansson B, Fredholm BB, et al. Adenosine $A_{2 A}$ receptors stimulate acetylcholine release from nerve terminals of the rat hippocampus. Neurosci Lett. 1995;196:41-44.

159. Rodrigues RJ, Canas PM, Lopes LV, et al. Modification of adenosine modulation of acetylcholine release in the hippocampus of aged rats. Neurobiol Aging. 2008;29: 1597-1601.

160. Barraco RA, Helfman CC, Anderson GF. Augmented release of serotonin by adenosine $\mathrm{A}_{2 \mathrm{a}}$ receptor activation and desensitization by CGS 21680 in the rat nucleus tractus solitarius. Brain Res. 1996;733:155-161.

161. Okada M, Kawata Y, Murakami T, et al. Differential effects of adenosine receptor subtypes on release and reuptake of hippocampal serotonin. Eur J Neurosci. 1999;11:1-9.

162. Barraco RA, Clough-Helfman C, Goodwin BP, et al. Evidence for presynaptic adenosine $\mathrm{A}_{2 \mathrm{a}}$ receptors associated with norepinephrine release and their desensitization in the rat nucleus tractus solitarius. J Neurochem. 1995;65: 1604-1611.

163. Mackiewicz M, Nikonova EV, Zimmermann JE, et al. Age-related changes in adenosine metabolic enzymes in sleep/wake regulatory areas of the brain. Neurobiol Aging. 2006;27:351-360.

164. Cunha RA, Constantino MC, Sebastião AM, et al. Modification of $\mathrm{A} 1$ and $\mathrm{A} 2 \mathrm{a}$ adenosine receptor binding in aged striatum, hippocampus and cortex of the rat. Neuroreport. 1995;6:1583-1588.

165. Sebastião AM, Cunha RA, de Mendonça A, et al. Modification of adenosine modulation of synaptic transmission in the hippocampus of aged rats. Br J Pharmacol. 2000;131:1629-1634.

166. Zhang C, Rissman RA, Feng J. Characterization of ATP alternations in an Alzheimer's disease transgenic mouse model. J Alzheimers Dis. 2015;44:375-378.

167. Alonso-Andrés P, Albasanz JL, Ferrer I, et al. Purinerelated metabolites and their converting enzymes are altered in frontal, parietal and temporal cortex at early stages of Alzheimer's disease pathology. Brain Pathol. 2018;28:933-946.

168. Li S, Li X, Guo H, et al. Intracellular ATP concentration contributes to the cytotoxic and cytoprotective effects of adenosine. PLoS One. 2013;8:e76731.

169. Perez Ortiz JM, Swerdlow RH. Mitochondrial dysfunction in Alzheimer's disease: Role in pathogenesis and novel therapeutic opportunities. $\mathrm{Br} \mathrm{J}$ Pharmacol. 2019. [Epub ahead of print]; DOI: 10.1111/bph.14585.

170. Lanser AJ, Rezende RM, Rubino S, et al. Disruption of the ATP/adenosine balance in $\mathrm{CD} 39^{-/-}$mice is associated 
with handling-induced seizures. Immunology. 2017;152: 589-601.

171. Kao Y-H, Lin M-S, Chen C-M, et al. Targeting ENT1 and adenosine tone for the treatment of Huntington's disease. Hum Mol Genet. 2017;26:467-478.

172. Lee C-C, Chang C-P, Lin C-J, et al. Adenosine augmentation evoked by an ENT1 inhibitor improves memory impairment and neuronal plasticity in the APP/PS1 mouse model of Alzheimer's disease. Mol Neurobiol. 2018;55:8936-8952.

173. Sebastião AM, Stone TW, Ribeiro JA. The inhibitory adenosine receptor at the neuromuscular junction and hippocampus of the rat: Antagonism by 1,3,8-substituted xanthines. Br J Pharmacol. 1990;101:453-459.

174. Lazarus M, Chen J-F, Huang Z-L, et al. Adenosine and sleep. In: Handbook of Experimental Pharmacology. Berlin: Springer, Berlin, Heidelberg; 2017.

175. Cunha RA, Milusheva E, Vizi ES, et al. Excitatory and inhibitory effects of $\mathrm{A} 1$ and $\mathrm{A} 2 \mathrm{~A}$ adenosine receptor activation on the electrically evoked $[3 \mathrm{H}]$ acetylcholine release from different areas of the rat hippocampus. J Neurochem. 1994;63:207-214.

176. Gonçalves ML, Cunha RA, Ribeiro JA. Adenosine $A_{2 A}$ receptors facilitate $45 \mathrm{Ca} 2+$ uptake through class $\mathrm{A}$ calcium channels in rat hippocampal CA3 but not CA1 synaptosomes. Neurosci Lett. 1997;238:73-77.

177. Mogul DJ, Adams ME, Fox AP. Differential activation of adenosine receptors decreases N-type but potentiates P-type $\mathrm{Ca}^{2+}$ current in hippocampal CA3 neurons. Neuron. 1993; 10:327-334.

178. Dias RB, Ribeiro JA, Sebastião AM. Enhancement of AMPA currents and GluR1 membrane expression through PKA-coupled adenosine A(2A) receptors. Hippocampus. 2012;22:276-291.

179. Rebola N, Lujan R, Cunha RA, et al. Adenosine $A_{2 A}$ receptors are essential for long-term potentiation of NMDA-EPSCs at hippocampal mossy fiber synapses. Neuron. 2008;57:121-134.

180. Tebano MT, Martire A, Rebola N, et al. Adenosine $\mathrm{A}_{2 \mathrm{~A}}$ receptors and metabotropic glutamate 5 receptors are co-localized and functionally interact in the hippocampus: A possible key mechanism in the modulation of $\mathrm{N}$ methyl-D-aspartate effects. J Neurochem. 2005;95: 1188-1200.

181. Sarantis K, Tsiamaki E, Kouvaros S, et al. Adenosine $\mathrm{A}_{2} \mathrm{~A}$ receptors permit mGluR5-evoked tyrosine phosphorylation of NR2B (Tyr1472) in rat hippocampus: A possible key mechanism in NMDA receptor modulation. J Neurochem. 2015;135:714-726.

182. Kouvaros S, Papatheodoropoulos C. Major dorsoventral differences in the modulation of the local CA1 hippocampal network by NMDA, mGlu5, adenosine A2A and cannabinoid CB1 receptors. Neuroscience. 2016; 317:47-64.

183. Correia-de-Sá P, Ribeiro JA. Potentiation by tonic A2aadenosine receptor activation of CGRP-facilitated $[3 \mathrm{H}]-\mathrm{ACh}$ release from rat motor nerve endings. $\mathrm{Br} \mathbf{J}$ Pharmacol. 1994;111:582-588.

184. Sebastião AM, Macedo MP, Ribeiro JA. Tonic activation of A2A adenosine receptors unmasks, and of A1 receptors prevents, a facilitatory action of calcitonin gene-related peptide in the rat hippocampus. Br J Pharmacol. 2000;129:374-380.
185. Diógenes MJ, Assaife-Lopes N, Pinto-Duarte A, et al. Influence of age on BDNF modulation of hippocampal synaptic transmission: Interplay with adenosine $\mathrm{A}_{2 \mathrm{~A}}$ receptors. Hippocampus. 2007; 17:577-585.

186. Diógenes MJ, Fernandes CC, Sebastião AM, et al. Activation of adenosine $\mathrm{A}_{2 \mathrm{~A}}$ receptor facilitates brainderived neurotrophic factor modulation of synaptic transmission in hippocampal slices. J Neurosci. 2004; 24:2905-2913.

187. Fontinha BM, Diógenes MJ, Ribeiro JA, et al. Enhancement of long-term potentiation by brainderived neurotrophic factor requires adenosine $A_{2 A}$ receptor activation by endogenous adenosine. Neuropharmacology. 2008;54:924-933.

188. Ferreira SG, Gonçalves FQ, Marques JM, et al. Presynaptic adenosine $\mathrm{A}_{2 \mathrm{~A}}$ receptors dampen cannabinoid CB1 receptor-mediated inhibition of corticostriatal glutamatergic transmission. Br J Pharmacol. 2015;172: 1074-1086.

189. Martire A, Tebano MT, Chiodi V, et al. Pre-synaptic adenosine $\mathrm{A}_{2 \mathrm{~A}}$ receptors control cannabinoid $\mathrm{CB} 1$ receptor-mediated inhibition of striatal glutamatergic neurotransmission. J Neurochem. 2011;116:273-280.

190. Ledent C, Vaugeois JM, Schiffmann SN, et al. Aggressiveness, hypoalgesia and high blood pressure in mice lacking the adenosine $\mathrm{A}_{2 \mathrm{a}}$ receptor. Nature. 1997;388: 674-678.

191. Wang JH, Ma YY, van den Buuse M. Improved spatial recognition memory in mice lacking adenosine $\mathrm{A}_{2 \mathrm{~A}}$ receptors. Exp Neurol. 2006; 199:438-445.

192. Zhou S-J, Zhu M-E, Shu D, et al. Preferential enhancement of working memory in mice lacking adenosine A(2A) receptors. Brain Res. 2009;1303:74-83.

193. Ferreira DG, Temido-Ferreira M, Miranda HV, et al. $\alpha$ Synuclein interacts with $\operatorname{PrP}(\mathrm{C})$ to induce cognitive impairment through mGluR5 and NMDAR2B. Nat Neurosci. 2017;20:1569-1579.

194. Simons SB, Caruana DA, Zhao M, et al. Caffeineinduced synaptic potentiation in hippocampal CA2 neurons. Nat Neurosci. 2011;15:23-25.

195. Laurent C, Burnouf S, Ferry B, et al. A2A adenosine receptor deletion is protective in a mouse model of Tauopathy. Mol Psychiatry. 2016;21:97-107.

196. Batalha VL, Ferreira DG, Coelho JE, et al. The caffeine-binding adenosine $\mathrm{A}_{2 \mathrm{~A}}$ receptor induces agelike HPA-axis dysfunction by targeting glucocorticoid receptor function. Sci Rep. 2016;6:31493.

197. Lopes LV, Cunha RA, Ribeiro JA. Increase in the number, $G$ protein coupling, and efficiency of facilitatory adenosine $\mathrm{A}_{2 \mathrm{~A}}$ receptors in the limbic cortex, but not striatum, of aged rats. J Neurochem. 1999;73: 1733-1738.

198. Canas PM, Duarte JMN, Rodrigues RJ, et al. Modification upon aging of the density of presynaptic modulation systems in the hippocampus. Neurobiol Aging. 2009;30:1877-1884.

199. Costenla AR, Diógenes MJ, Canas PM, et al. Enhanced role of adenosine $\mathrm{A}(2 \mathrm{~A})$ receptors in the modulation of LTP in the rat hippocampus upon ageing. Eur J Neurosci. 2011;34:12-21.

200. Brakeman PR, Lanahan AA, O'Brien R, et al. Homer: A protein that selectively binds metabotropic glutamate receptors. Nature. 1997;386:284-288. 
201. Tu JC, Xiao B, Naisbitt S, et al. Coupling of mGluR/Homer and PSD-95 complexes by the Shank family of postsynaptic density proteins. Neuron. 1999; 23:583-592.

202. Roche KW, Tu JC, Petralia RS, et al. Homer $1 \mathrm{~b}$ regulates the trafficking of group I metabotropic glutamate receptors. J Biol Chem. 1999;274:25953-25957.

203. Jia Z, Lu Y, Henderson J, et al. Selective abolition of the NMDA component of long-term potentiation in mice lacking mGluR5. Learn Mem. 1998;5:331-343.

204. Ugolini A, Corsi M, Bordi F. Potentiation of NMDA and AMPA responses by the specific mGluR5 agonist CHPG in spinal cord motoneurons. Neuropharmacology. 1999;38:1569-1576.

205. Awad H, Hubert GW, Smith Y, et al. Activation of metabotropic glutamate receptor 5 has direct excitatory effects and potentiates NMDA receptor currents in neurons of the subthalamic nucleus. J Neurosci. 2000;20: 7871-7879.

206. Mannaioni G, Marino MJ, Valenti O, et al. Metabotropic glutamate receptors 1 and 5 differentially regulate CA1 pyramidal cell function. J Neurosci. 2001; 21:5925-5934.

207. Lee G, Thangavel R, Sharma VM, et al. Phosphorylation of Tau by Fyn: Implications for Alzheimer's disease. J Neurosci. 2004;24:2304-2312.

208. Ittner LM, Ke YD, Delerue F, et al. Dendritic function of tau mediates amyloid-beta toxicity in Alzheimer's disease mouse models. Cell. 2010;142: 387-397.

209. Tezuka T, Umemori H, Akiyama T, et al. PSD-95 promotes Fyn-mediated tyrosine phosphorylation of the Nmethyl-D-aspartate receptor subunit NR2A. Proc Natl Acad Sci U S A. 1999;96:435-440.

210. Köhr G, Seeburg PH. Subtype-specific regulation of recombinant NMDA receptor-channels by protein tyrosine kinases of the src family. J Physiol. 1996;492 (Pt 2):445-452.

211. Lopes LV, Cunha RA, Ribeiro JA. Cross talk between $\mathrm{A}(1)$ and $\mathrm{A}(2 \mathrm{~A})$ adenosine receptors in the hippocampus and cortex of young adult and old rats. J Neurophysiol. 1999;82:3196-3203.

212. Ciruela F, Casadó V, Rodrigues RJ, et al. Presynaptic control of striatal glutamatergic neurotransmission by adenosine $\mathrm{A} 1-\mathrm{A}_{2 \mathrm{~A}}$ receptor heteromers. J Neurosci. 2006;26:2080-2087.

213. Ferré S, Ciruela F, Quiroz C, et al. Adenosine receptor heteromers and their integrative role in striatal function. ScientificWorldJournal. 2007;7:74-85.

214. Canhão P, de Mendonça A, Ribeiro JA. 1,3-Dipropyl-8cyclopentylxanthine attenuates the NMDA response to hypoxia in the rat hippocampus. Brain Res. 1994;661: 265-273.

215. Klishin A, Lozovaya N, Krishtal O. A1 adenosine receptors differentially regulate the N-methyl-D-aspartate and non-N-methyl-D-aspartate receptor-mediated components of hippocampal excitatory postsynaptic current in a $\mathrm{Ca} 2+/ \mathrm{Mg}(2+)$-dependent manner. Neuroscience. 1995;65:947-953.

216. Chiodi V, Ferrante A, Ferraro L, et al. Striatal adenosinecannabinoid receptor interactions in rats over-expressing adenosine $A_{2 A}$ receptors. J Neurochem. 2016;136:907917.
217. Orr AG, Hsiao EC, Wang MM, et al. Astrocytic adenosine receptor A2A and Gs-coupled signaling regulate memory. Nat Neurosci. 2015;18:423-434.

218. Albasanz JL, Rodríguez A, Ferrer I, et al. Adenosine $\mathrm{A}_{2 \mathrm{~A}}$ receptors are up-regulated in Pick's disease frontal cortex. Brain Pathol. 2006;16:249-255.

219. Dall'Igna OP, Fett P, Gomes MW, et al. Caffeine and adenosine $\mathrm{A}(2 \mathrm{a})$ receptor antagonists prevent betaamyloid (25-35)-induced cognitive deficits in mice. Exp Neurol. 2007;203:241-245.

220. Matos M, Augusto E, Machado NJ, et al. Astrocytic adenosine $\mathrm{A}_{2 \mathrm{~A}}$ receptors control the amyloid- $\beta$ peptideinduced decrease of glutamate uptake. J Alzheimers Dis. 2012;31:555-567.

221. Canas PM, Porciuncula LO, Cunha GMA, et al. Adenosine $A_{2 A}$ receptor blockade prevents synaptotoxicity and memory dysfunction caused by beta-amyloid peptides via p38 mitogen-activated protein kinase pathway. J Neurosci. 2009;29:14741-14751.

222. Viana da Silva S, Haberl MG, Zhang P, et al. Early synaptic deficits in the APP/PS1 mouse model of Alzheimer's disease involve neuronal adenosine $\mathrm{A}_{2 \mathrm{~A}}$ receptors. Nat Commun. 2016;7:11915.

223. Li P, Rial D, Canas PM, et al. Optogenetic activation of intracellular adenosine $A_{2 A}$ receptor signaling in the hippocampus is sufficient to trigger CREB phosphorylation and impair memory. Mol Psychiatry. 2015;20: 1339-1349.

224. Batalha VL, Pego JM, Fontinha BM, et al. Adenosine $\mathrm{A}(2 \mathrm{~A})$ receptor blockade reverts hippocampal stressinduced deficits and restores corticosterone circadian oscillation. Mol Psychiatry. 2013;18:320-331.

225. Barros-Barbosa AR, Ferreirinha F, Oliveira Â, et al. Adenosine $\mathrm{A}_{2 \mathrm{~A}}$ receptor and ecto-5'-nucleotidase/ CD73 are upregulated in hippocampal astrocytes of human patients with mesial temporal lobe epilepsy (MTLE). Purinergic Signal. 2016;12:719-734.

226. Canas PM, Porciúncula LO, Simões AP, et al. Neuronal adenosine $\mathrm{A}_{2 \mathrm{~A}}$ receptors are critical mediators of neurodegeneration triggered by convulsions. eNeuro. 2018:5. DOI: 10.1523/ENEURO.0385-18.2018.

227. Albasanz JL, Perez S, Barrachina M, et al. Upregulation of adenosine receptors in the frontal cortex in Alzheimer's disease. Brain Pathol. 2008;18:211219.

228. Horgusluoglu-Moloch E, Nho K, Risacher SL, et al. Targeted neurogenesis pathway-based gene analysis identifies ADORA2A associated with hippocampal volume in mild cognitive impairment and Alzheimer's disease. Neurobiol Aging. 2017;60:92-103.

229. Lee Y-C, Chien C-L, Sun C-N, et al. Characterization of the rat $\mathrm{A} 2 \mathrm{~A}$ adenosine receptor gene: $\mathrm{A} 4.8 \mathrm{-kb}$ promoter-proximal DNA fragment confers selective expression in the central nervous system. Eur J Neurosci. 2003;18:1786-1796.

230. Chu YY, Tu KH, Lee YC, et al. Characterization of the rat A2a adenosine receptor gene. DNA Cell Biol. 1996; 15:329-337.

231. Kreth S, Ledderose C, Kaufmann I, et al. Differential expression of 5'-UTR splice variants of the adenosine $\mathrm{A}_{2 \mathrm{~A}}$ receptor gene in human granulocytes: Identification, characterization, and functional impact on activation. FASEB J. 2008;22:3276-3286. 
232. Mouilleron H, Delcourt V, Roucou X. Death of a dogma: Eukaryotic mRNAs can code for more than one protein. Nucleic Acids Res. 2016;44:14-23.

233. Andreev DE, O'Connor PB, Zhdanov AV, et al. Oxygen and glucose deprivation induces widespread alterations in mRNA translation within 20 minutes. Genome Biol. 2015;16:90.

234. Lee YC, Chang CW, Su CW, et al. The $5^{\prime}$ untranslated regions of the rat $\mathrm{A} 2 \mathrm{~A}$ adenosine receptor gene function as negative translational regulators. J Neurochem. 1999;73:1790-1798.

235. Liang H. A genome-wide study of dual coding regions in human alternatively spliced genes. Genome Res. 2005;16:190-196.

236. Klemke $M$. Two overlapping reading frames in a single exon encode interacting proteins - a novel way of gene usage. EMBO J. 2001;20:3849-3860.

237. Lee $\mathrm{C}$, Lai $\mathrm{H}-\mathrm{L}$, Lee $\mathrm{Y}-\mathrm{C}$, et al. The $\mathrm{A}_{2 \mathrm{~A}}$ adenosine receptor is a dual coding gene: A novel mechanism of gene usage and signal transduction. J Biol Chem. 2014;289:1257-1270.

238. Chiang M-C, Lee Y-C, Huang C-L, et al. cAMPresponse element-binding protein contributes to suppression of the $\mathrm{A} 2 \mathrm{~A}$ adenosine receptor promoter by mutant Huntingtin with expanded polyglutamine residues. J Biol Chem. 2005;280:14331-14340.

239. Xie X, Jhaveri KA, Ding M, et al. Expression of striatal adenosine and dopamine receptors in mice deficient in the p50 subunit of NF-kappaB. Life Sci. 2007;81: 1031-1041.

240. Lee YC, Lai HL, Sun CN, et al. Identification of nuclear factor 1 (NF1) as a transcriptional modulator of rat $\mathrm{A}(2 \mathrm{~A})$ adenosine receptor. Brain Res Mol Brain Res. 2003;111:61-73.

241. Buira SP, Albasanz JL, Dentesano G, et al. DNA methylation regulates adenosine $\mathrm{A}(2 \mathrm{~A})$ receptor cell surface expression levels. J Neurochem. 2010;112: $1273-1285$

242. Buira SP, Dentesano G, Albasanz JL, et al. DNA methylation and Yin Yang-1 repress adenosine $\mathrm{A}_{2 \mathrm{~A}}$ receptor levels in human brain. J Neurochem. 2010; 115:283-295.

243. Villar-Menéndez I, Porta S, Buira SP, et al. Increased striatal adenosine $\mathrm{A}_{2 \mathrm{~A}}$ receptor levels is an early event in Parkinson's disease-related pathology and it is potentially regulated by miR-34b. Neurobiol Dis. 2014;69:206-214.

244. Villar-Menéndez I, Blanch M, Tyebji S, et al. Increased 5methylcytosine and decreased 5-hydroxymethylcytosine levels are associated with reduced striatal A2AR levels in Huntington's disease. Neuromolecular Med. 2013;15: 295-309.

245. Villar-Menéndez I, Díaz-Sánchez S, Blanch M, et al. Reduced striatal adenosine $\mathrm{A}_{2 \mathrm{~A}}$ receptor levels define a molecular subgroup in schizophrenia. J Psychiatr Res. 2014;51:49-59.

246. Villar-Menéndez I, Nuñez F, Díaz-Sánchez S, et al. Striatal adenosine $\mathrm{A}_{2 \mathrm{~A}}$ receptor expression is controlled by $\mathrm{S}$-adenosyl-L-methionine-mediated methylation. Purinergic Signal. 2014;10:523-528.

247. Heyn J, Ledderose C, Hinske LC, et al. Adenosine $\mathrm{A}_{2 \mathrm{~A}}$ receptor upregulation in human PMNs is controlled by miRNA-214, miRNA-15, and miRNA-16. Shock. 2012;37:156-163.

248. Zhao L, Liu Y-W, Yang T, et al. The mutual regulation between miR-214 and A2AR signaling plays an important role in inflammatory response. Cell Signal. 2015; 27:2026-2034.

249. He X, Hu J-L, Li J, et al. A feedback loop in PPAR $\gamma$ adenosine $\mathrm{A}_{2 \mathrm{~A}}$ receptor signaling inhibits inflammation and attenuates lung damages in a mouse model of LPSinduced acute lung injury. Cell Signal. 2013;25:19131923.

250. Bruzzese L, Fromonot J, By Y, et al. NF- $\kappa \mathrm{B}$ enhances hypoxia-driven T-cell immunosuppression via upregulation of adenosine $\mathrm{A}(2 \mathrm{~A})$ receptors. Cell Signal. 2014;26:1060-1067.

251. Morello S, Ito K, Yamamura S, et al. IL-1 beta and TNF-alpha regulation of the adenosine receptor (A2A) expression: Differential requirement for NFkappa B binding to the proximal promoter. J Immunol. 2006;177:7173-7183.

252. Williams-Karnesky RL, Sandau US, Lusardi TA, et al. Epigenetic changes induced by adenosine augmentation therapy prevent epileptogenesis. J Clin Invest. 2013; 123:3552-3563.

253. Huang $\mathrm{A}, \mathrm{Wu} \mathrm{H}$, Iriyama $\mathrm{T}$, et al. Elevated adenosine induces placental DNA hypomethylation independent of A2B receptor signaling in preeclampsia. Hypertension. 2017;70:209-218.

254. Xu Y, Wang Y, Yan S, et al. Intracellular adenosine regulates epigenetic programming in endothelial cells to promote angiogenesis. EMBO Mol Med. 2017;9: 1263-1278.

255. Smith A. Effects of caffeine on human behavior. Food Chem Toxicol. 2002;40:1243-1255.

256. van Gelder BM, Buijsse B, Tijhuis M, et al. Coffee consumption is inversely associated with cognitive decline in elderly European men: The FINE Study. Eur J Clin Nutr. 2007;61:226-232.

257. Ritchie K, Carrière I, de Mendonca A, et al. The neuroprotective effects of caffeine: A prospective population study (the Three City Study). Neurology. 2007;69:536-545.

258. Maia L, de Mendonça A. Does caffeine intake protect from Alzheimer's disease? Eur J Neurol. 2002;9:377382.

259. Lindsay J, Laurin D, Verreault R, et al. Risk factors for Alzheimer's disease: A prospective analysis from the Canadian Study of Health and Aging. Am J Epidemiol. 2002;156:445-453.

260. Eskelinen MH, Ngandu T, Tuomilehto J, et al. Midlife coffee and tea drinking and the risk of late-life dementia: A population-based CAIDE study. J Alzheimers Dis. 2009;16:85-91.

261. Cao C, Loewenstein DA, Lin X, et al. High Blood caffeine levels in MCI linked to lack of progression to dementia. J Alzheimers Dis. 2012;30:559-572.

262. Gelber RP, Petrovitch H, Masaki KH, et al. Coffee intake in midlife and risk of dementia and its neuropathologic correlates. J Alzheimers Dis. 2011;23: 607-615.

263. Ascherio A, Zhang SM, Hernán MA, et al. Prospective study of caffeine consumption and risk of Parkinson's disease in men and women. Ann Neurol. 2001;50:56-63. 
264. Ross GW, Abbott RD, Petrovitch H, et al. Association of coffee and caffeine intake with the risk of Parkinson disease. JAMA. 2000;283:2674-2679.

265. Popat RA, Van Den Eeden SK, Tanner CM, et al. Coffee, ADORA2A, and CYP1A2: The caffeine connection in Parkinson's disease. Eur J Neurol. 2011;18:756-765.

266. Fredholm BB. Adenosine actions and adenosine receptors after 1 week treatment with caffeine. Acta Physiol Scand. 1982;115:283-286.

267. Fredholm BB. Astra Award Lecture. Adenosine, adenosine receptors and the actions of caffeine. Pharmacol Toxicol. 1995;76:93-101.

268. Huang Z-L, Qu W-M, Eguchi N, et al. Adenosine A2A, but not A1, receptors mediate the arousal effect of caffeine. Nat Neurosci. 2005;8:858-859.

269. El Yacoubi M, Ledent C, Parmentier M, et al. Reduced appetite for caffeine in adenosine $\mathrm{A}(2 \mathrm{~A})$ receptor knockout mice. Eur J Pharmacol. 2005;519:290-291.

270. Alsene K, Deckert J, Sand P, et al. Association between $A_{2 a}$ receptor gene polymorphisms and caffeine-induced anxiety. Neuropsychopharmacology. 2003;28:1694-1702.

271. Cornelis MC, El-Sohemy A, Campos H. Genetic polymorphism of the adenosine $\mathrm{A}_{2 \mathrm{~A}}$ receptor is associated with habitual caffeine consumption. Am J Clin Nutr. 2007;86:240-244.

272. Kolahdouzan M, Hamadeh MJ. The neuroprotective effects of caffeine in neurodegenerative diseases. CNS Neurosci Ther. 2017;23:272-290.

273. Costa MS, Botton PH, Mioranzza S, et al. Caffeine prevents age-associated recognition memory decline and changes brain-derived neurotrophic factor and tirosine kinase receptor $(\mathrm{TrkB})$ content in mice. Neuroscience. 2008;153:1071-1078.

274. Kaster MP, Machado NJ, Silva HB, et al. Caffeine acts through neuronal adenosine $\mathrm{A}_{2 \mathrm{~A}}$ receptors to prevent mood and memory dysfunction triggered by chronic stress. Proc Natl Acad Sci U S A. 2015;112:7833-7838.

275. Arendash GW, Schleif W, Rezai-Zadeh K, et al. Caffeine protects Alzheimer's mice against cognitive impairment and reduces brain beta-amyloid production. Neuroscience. 2006;142:941-952.

276. Arendash GW, Mori T, Cao C, et al. Caffeine reverses cognitive impairment and decreases brain amyloid-beta levels in aged Alzheimer's disease mice. J Alzheimers Dis. 2009;17:661-680.

277. Chu Y-F, Chang W-H, Black RM, et al. Crude caffeine reduces memory impairment and amyloid $\beta(1-42)$ lev- els in an Alzheimer's mouse model. Food Chem. 2012; 135:2095-2102.

278. Laurent C, Eddarkaoui S, Derisbourg M, et al. Beneficial effects of caffeine in a transgenic model of Alzheimer's disease-like tau pathology. Neurobiol Aging. 2014;35:2079-2090.

279. Matos M, Augusto E, Agostinho P, et al. Antagonistic interaction between adenosine $\mathrm{A} 2 \mathrm{~A}$ receptors and $\mathrm{Na}+/ \mathrm{K}+$-ATPase- 2 controlling glutamate uptake in astrocytes. J Neurosci. 2013;33:18492-18502.

280. Hindley S, Herman MA, Rathbone MP. Stimulation of reactive astrogliosis in vivo by extracellular adenosine diphosphate or an adenosine A2 receptor agonist. J Neurosci Res. 1994;38:399-406.

281. Orr AG, Orr AL, Li X-J, et al. Adenosine A(2A) receptor mediates microglial process retraction. Nat Neurosci. 2009;12:872-878.

282. Fiebich BL, Biber K, Lieb K, et al. Cyclooxygenase-2 expression in rat microglia is induced by adenosine A2a-receptors. Glia. 1996;18:152-160.

283. Gomes C, Ferreira R, George J, et al. Activation of microglial cells triggers a release of brain-derived neurotrophic factor (BDNF) inducing their proliferation in an adenosine $\mathrm{A} 2 \mathrm{~A}$ receptor-dependent manner: A2A receptor blockade prevents BDNF release and proliferation of microglia. J Neuroinflammation. 2013;10:16.

284. Saura J, Angulo E, Ejarque A, et al. Adenosine A2A receptor stimulation potentiates nitric oxide release by activated microglia. J Neurochem. 2005;95:919-929.

285. Heese K, Fiebich BL, Bauer J, Otten U. Nerve growth factor (NGF) expression in rat microglia is induced by adenosine A2a-receptors. Neurosci Lett. 1997;231:83-86.

286. Rebola N, Simões AP, Canas PM, et al. Adenosine $\mathrm{A} 2 \mathrm{~A}$ receptors control neuroinflammation and consequent hippocampal neuronal dysfunction. J Neurochem. 2011;117:100-111.

Address correspondence to: Luísa V. Lopes, PhD Instituto de Medicina Molecular João Lobo Antunes Faculdade de Medicina Universidade de Lisboa 1649-028 Lisboa Portugal

E-mail: lvlopes@medicina.ulisboa.pt 